\title{
تحليل المخططات المفاهيمية لخحاور الأنموذج الإيماني على مواقع الإنترنت العربية
}

حسن مظفر الرزو

مقدمة:

إن الأنموذج الإيماني الذي أرسى القر آن الكريم طوده الشامخَ لَبَنة، لَبنة، وحمــل

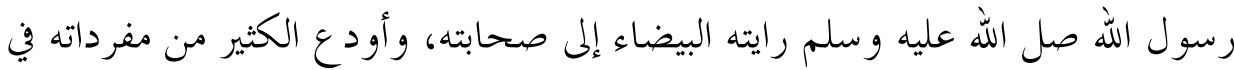
خطابه النبوي الشريف، يؤشر بوضوح على اهتمام الشارع الحلكيم بجميع عناصــــهـ ويؤكد في الوقت ذاته على أن التوحيد أساسه، وقاعدته، ومنطلقه. بوسئ.

وأصبح هذا الأنموذج (بجميع عناصره و التفاعلات القائمة بينها) القاعدة المعرفيــة التي تنطلق منها، وترجع إليها، وتنضبط بها، كل أفكار الإنسان المسلم، ومفاهيمــه،

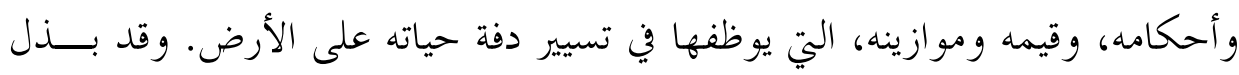

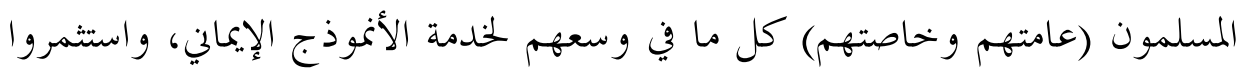
القدرات الكبيرة التي توفرها الشبكة العنكبوتية (الإنترنت)، فأودعوا خطاهـم المعرفي،

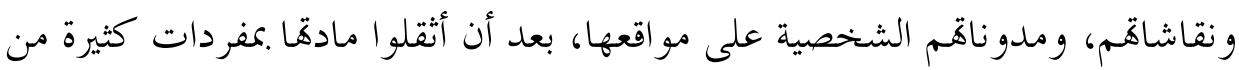
مفردات العقيدة الإسلامية.

وإذا كانت دراسة التيارات الفكرية تسعى الى قراءة خطاب علماء الأمة، الـــذي

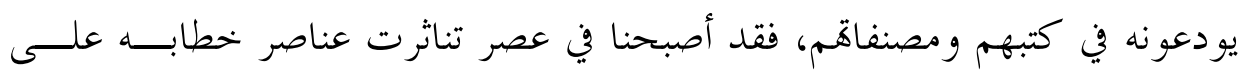

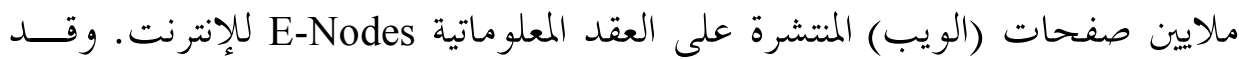

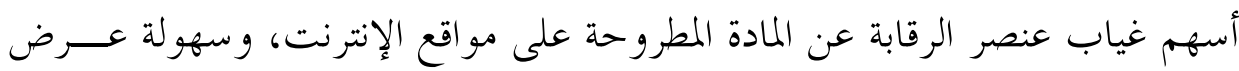

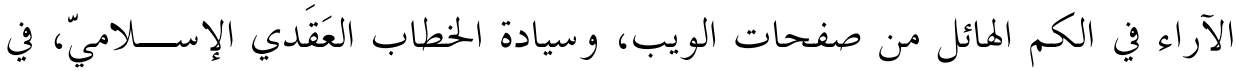

halrizzo@gmail.com مدير المكتب الاستشاري العلمي في كلية الحدباء الجامعة/ الموصل/ العراق. 
شحن البيئة الرقمية المعلوماتية بآراء كثيرة؛ إذ اختلط صحيحها بسقيمها، وتباينـــت مواردها، و التبست مفرداها.

ولهذا السبب، بات لزاماً علينا تتبع حر كة الخطاب العَقَدي الإسلامي، وسيرورته

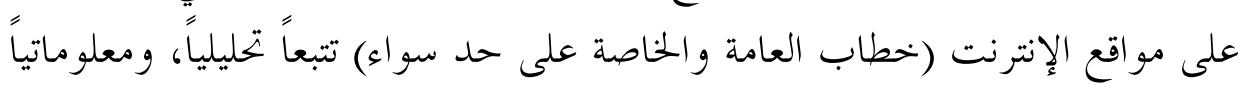

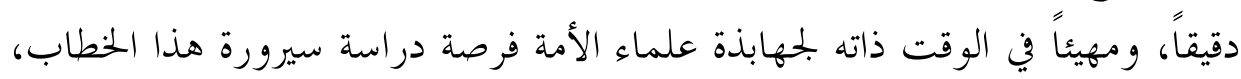

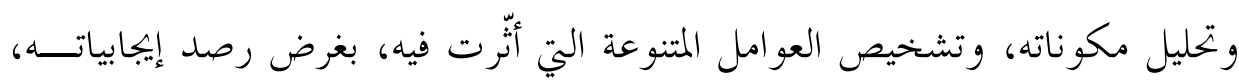

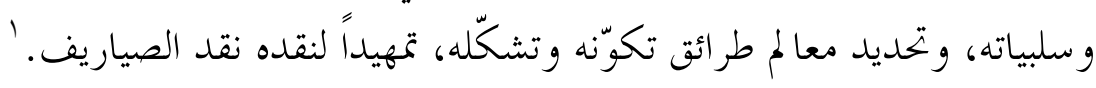
وقد تركزّ عملنا في هذا البحث على جمع مفردات منتخبة من منظومتنا العقديـــة

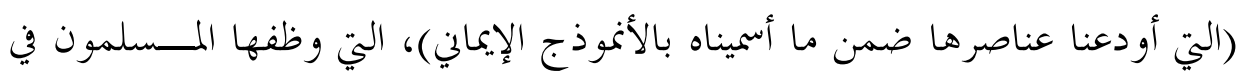

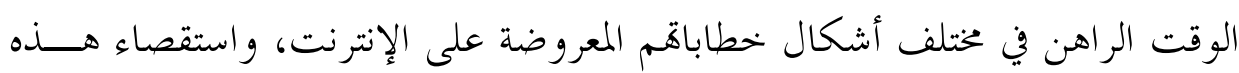

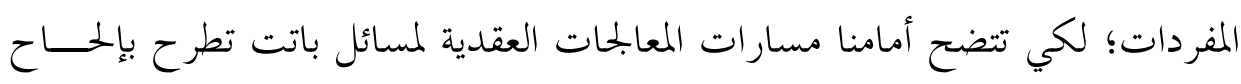
على المسلم المعاصر، مثل: الإيمان، و الكفر، و الفسق، و البدعة، و الضلالة.

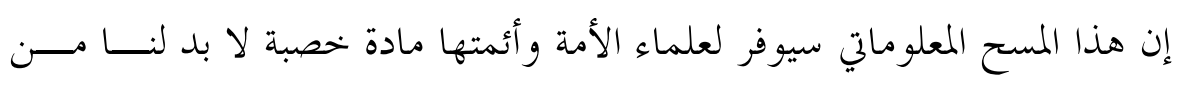

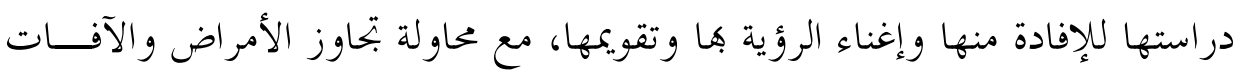

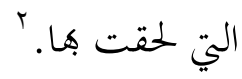

\section{أولاً: : الفضاءات المعلو ماتية للإنترنيت Info Spaces on The Net}

تعد منظومة الويب إحدى أنواع الفضاءات المعلوماتية Cyberspaces، التي تسود

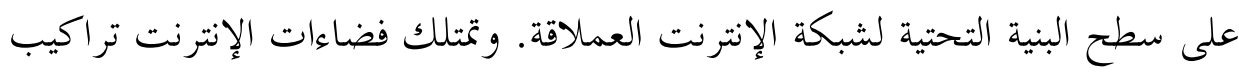

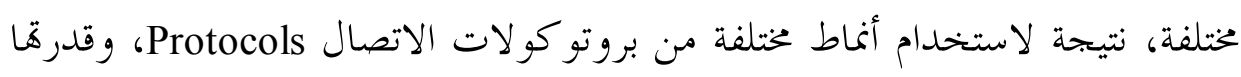
على توفير أساليب مختلفة لإبحار داخل حدود الفضاء المعلو ماتي، أو عند ممارسة أنشطة تفاعلية مع مفردات بيئته الرقمية.

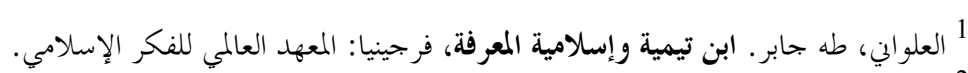

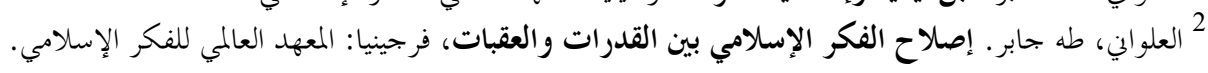




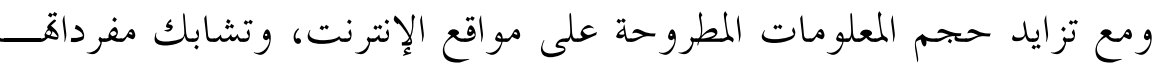

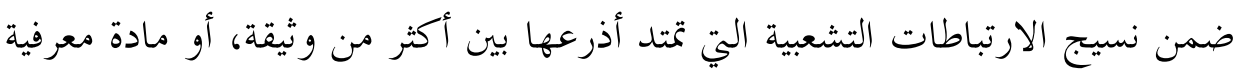

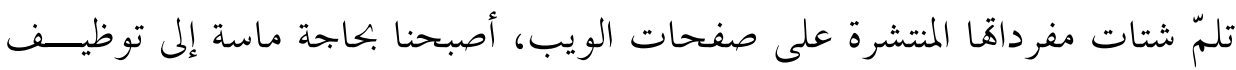

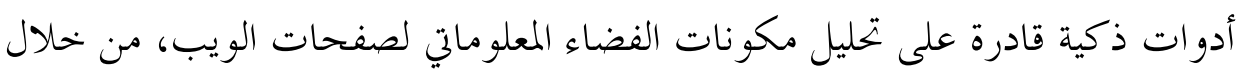

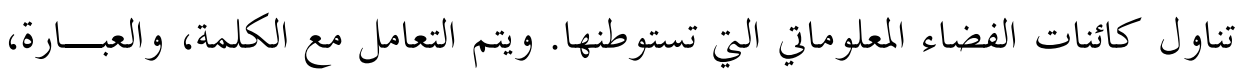

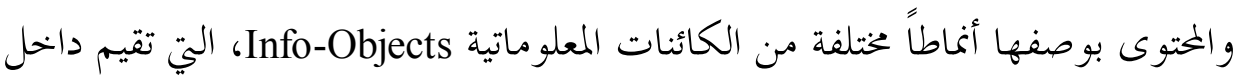

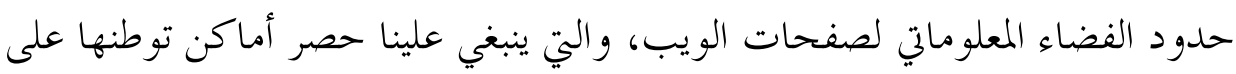

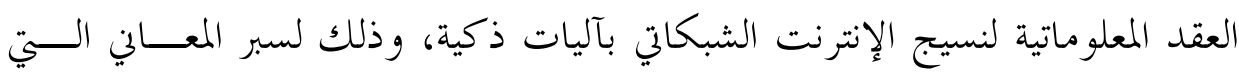
تستوطن في المختوى الرقمي لهذه الصفحات. الإنرنت الفبكاتي

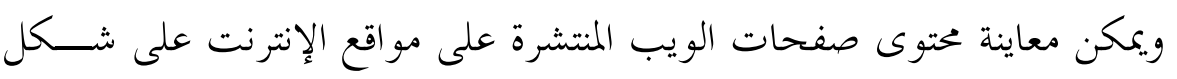

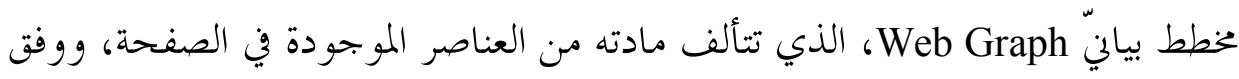

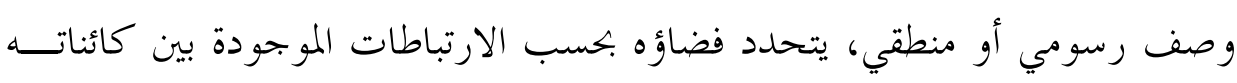

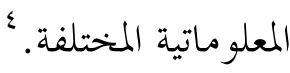

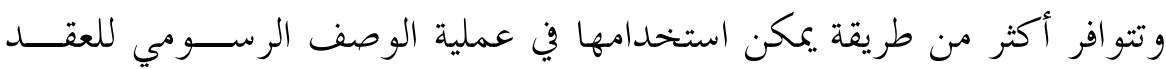

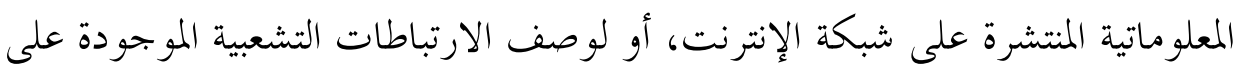

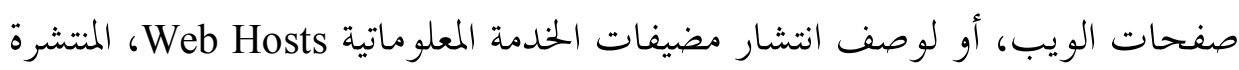

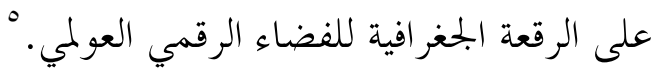
ويتسم مخطط الويب بميزات فريدة لا نكاد بخدها في مخططات أخرى، أهمها التغير

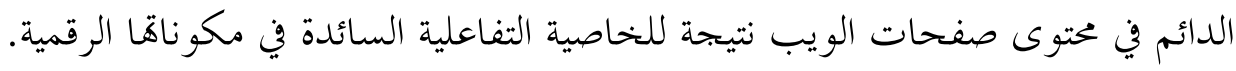

${ }^{3}$ Peter ,H. ,Alesso, H.P. \& C. Smith, (2006), Thinking On The Web Berners-Lee, Goodel, And Turing, John Wiley \& Sons, Inc., New Jersey, USA.

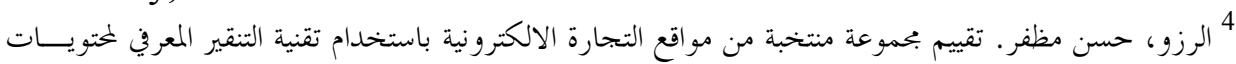

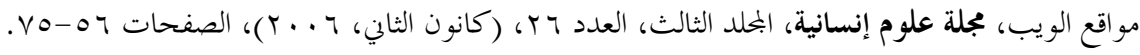

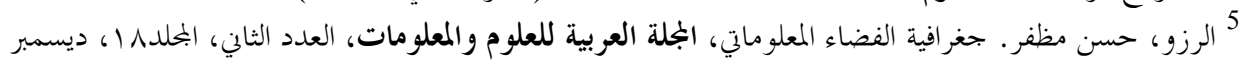




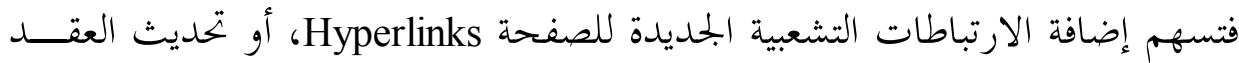

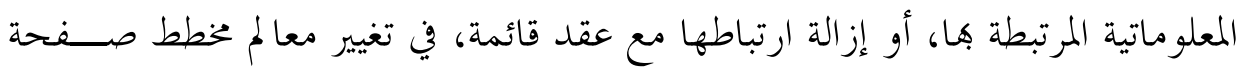

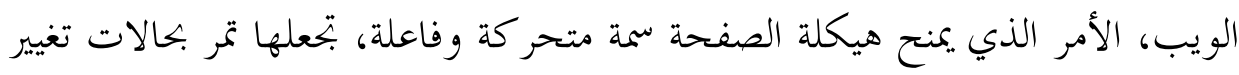
دائم

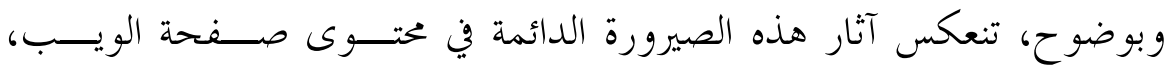

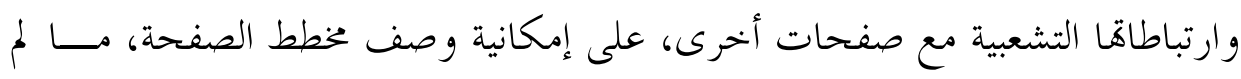

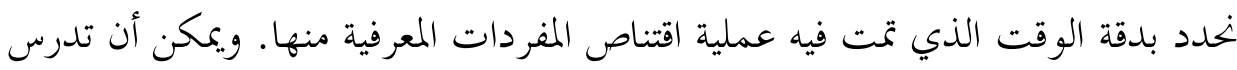

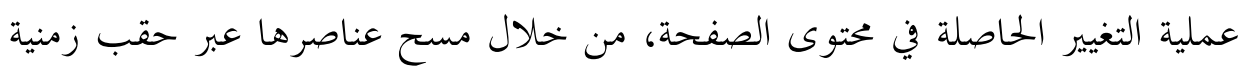
متباعدة؛ لتحديد أنماط التغيير التي سادت مادها.

وتكمن أهمية دراسة خخططات صفحات الويب، في أها تمنحنا فرصة جيدة لمعاينة

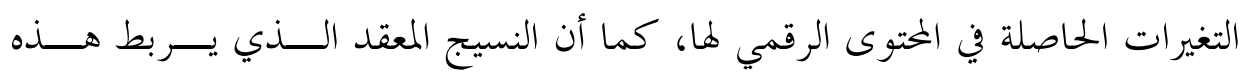

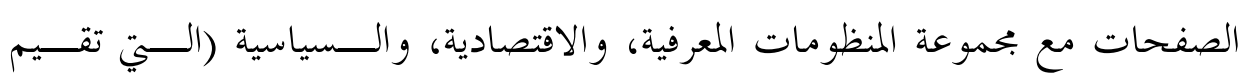

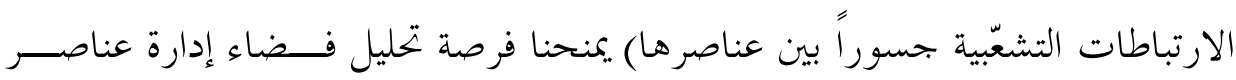

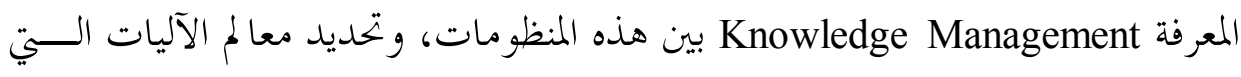
يو ظفها الإنسان المعاصر في التعامل مع الإشكاليات المعرفية القائمة.

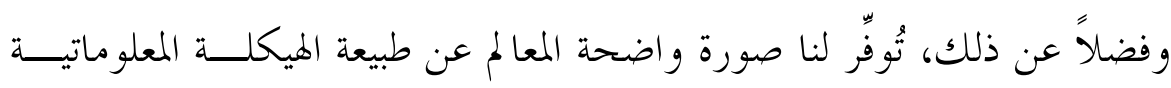

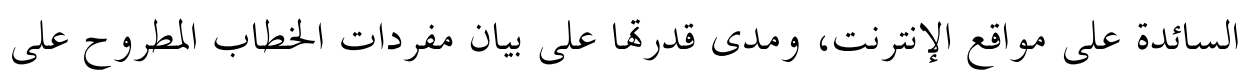

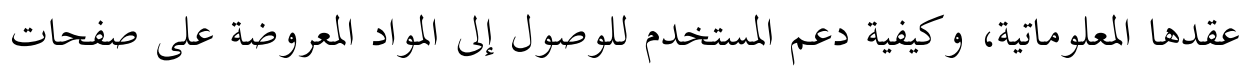

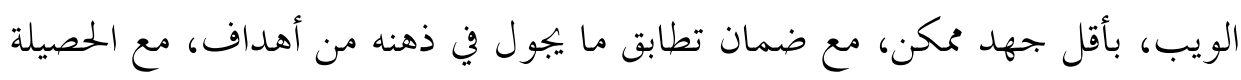

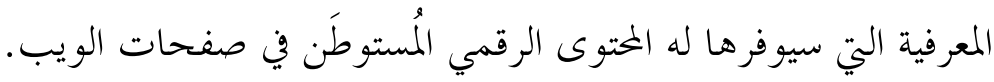

${ }^{6}$ Baldi ,P., Frasconi ,P. \& P. Smyth, (2003), Modeling the Internet and the Web, John Wiley \& Sons, England. 
أما عملية تحليل عناصر المحتوى، فتبدأ بصياغة قواعد منطقية قادرة على التنقير عن المفردة المعرفية التي نسعى للوصول إليها، مع تحديد العقدة المعلوماتية التي تنتمي إليها، وطبيعة الخطاب الذي وظّفت في مادته، ومقدار تكرارها في صفحات الويب.

\section{ثانياً: الأنموذج الإيماني غحتويات صفحات الويب}

يستخدم مصطلح الأنموذج Model (في دائرة المعالجات المحوسبة) بوصفه إنــشاءً تجريدياً يسعى إلى وصف ظاهرة، بواسطة بحموعة من العناصر التي ترتبط فيما بينــها،

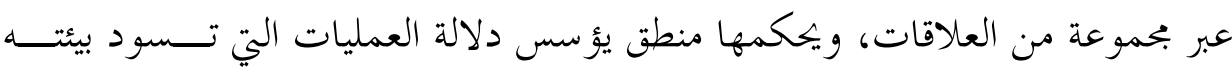
المعرفية.

ولتوفير بيئة مناسبة لحوسبة المفاهيم المعرفية، تبرز الحاجة إلى صياغة نسق رياضي/ منطقي، يصف الظاهرة التي نتناو لها بالدراسة و التحليل، و بنمط يمكن من خلاله مــنح أدوات الحوسبة القدرة على معالجتها، وسبر دلالتها. وعلى هذا الأساس بجد أنفسنا قبالة نسق معلوماتي - معر في تتألف مادته مــن بحموعة مدخحلات تغذي آلة اســتدلال معـــرفي Knowledge Inference Engine، تسودها بحموعة من القواعد المنطقية، التي تتلاءم مع طبيعة المسألة العلمية التي يتناولها

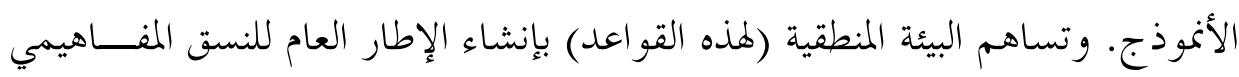
Paradigm الذي يهيمن على عملية سريان جميع العمليات المعرفية السائدة فيها.

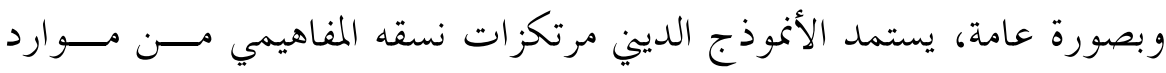

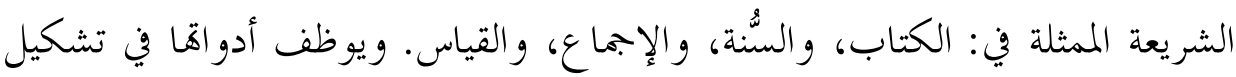
الإطار العام لتناول جملة من المسائل المطروحة على أرض الواقع.

${ }^{7}$ Wikipedia, (2007), The Free On-line Encyclopedia The Wikipedia Project, Available At: http://www.wikipedia.com 
ويضم الأنموذج الديني بحموعة متنوعة من النماذج الثانوية التي ترتكز إلى مـــادة

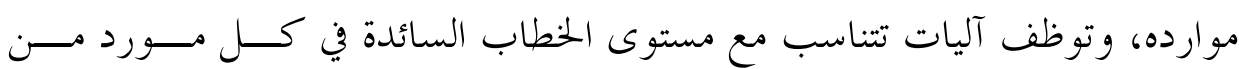

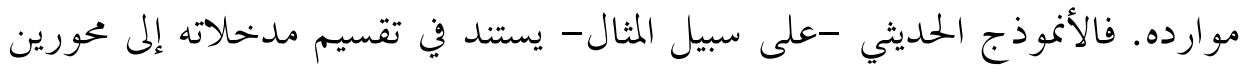

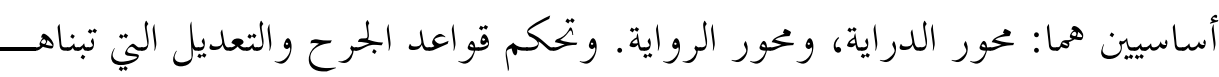

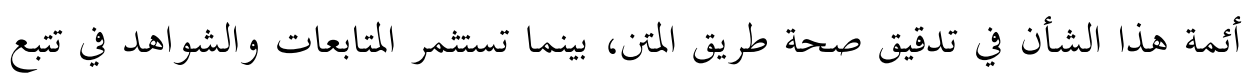
طرق الرواية، وتحديد العلل الكامنة في الروايات السقيمة.

وإذا حاولنا أن نوظف النسق المفاهيمي للأنموذج المحوسب على مسائل العقيـــة

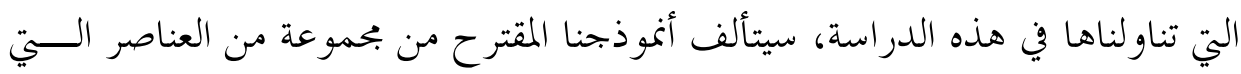

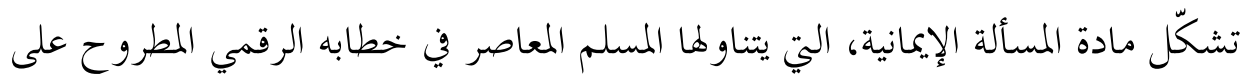

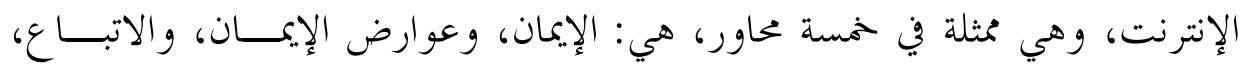
والبدع والمبتدعة، ورجال الإيمان ومناوئيهم.

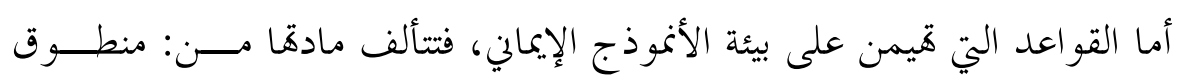

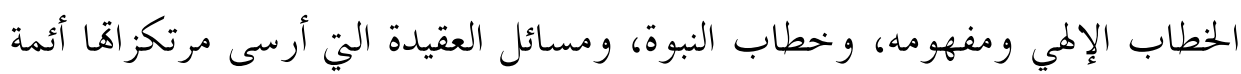

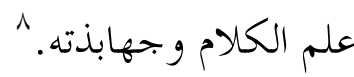

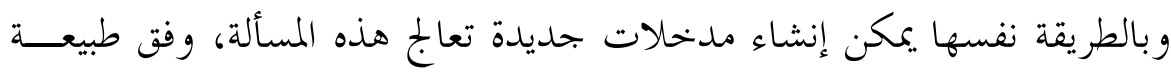

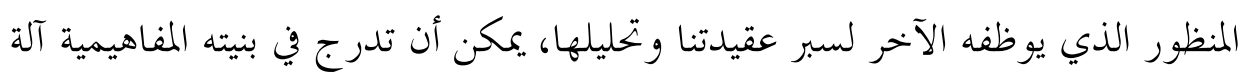

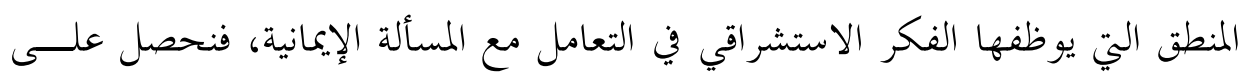

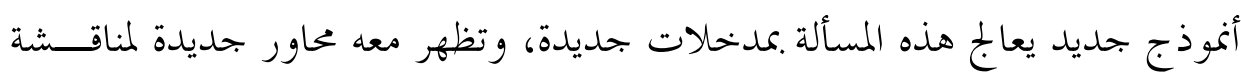
المسألة.

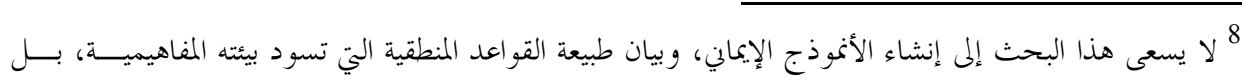

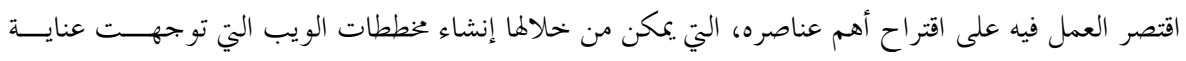
البحث إليها. 


\section{ثالثاً: إنشاء خارطة مفاهيمية للأنموذج المقترح}

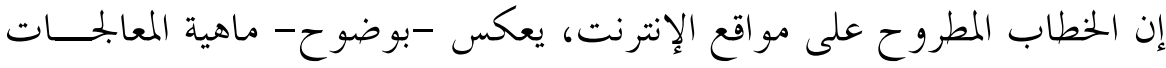

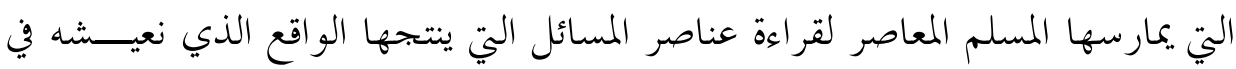
وقتنا الراهن.

وبعد أن أصبحت بيئة الإنترنت الوعاء الشامل، الذي يستوعب غختلف أشــكال

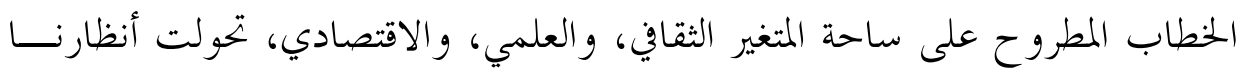

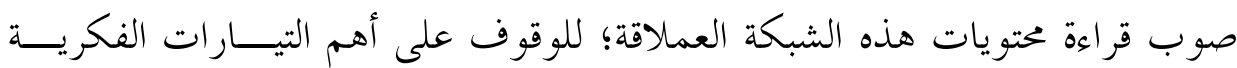

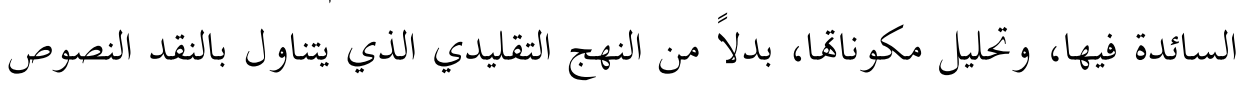

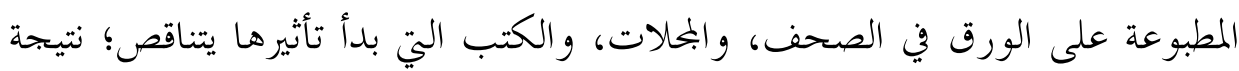
لتزايد حجم الفيض المعلوماتي الرقمي على الإنترنت. وتمرّ أمتنا الإسلامية منذ أكثر من عقد من الزمان، بمرحلة إعادة تشكيل المفاهيم

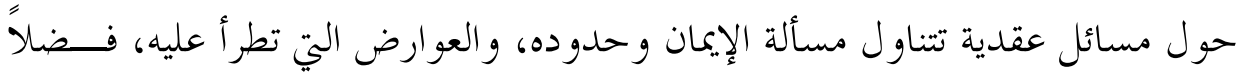

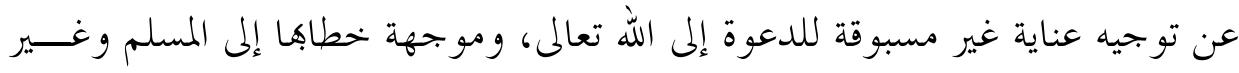

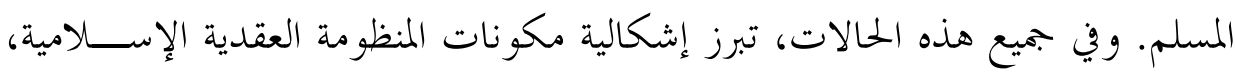

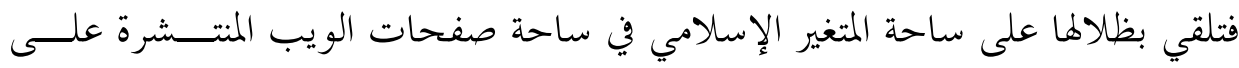

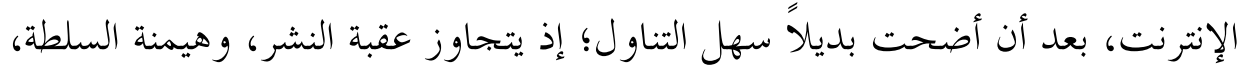

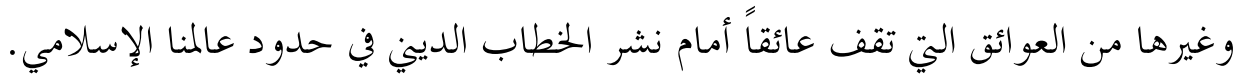

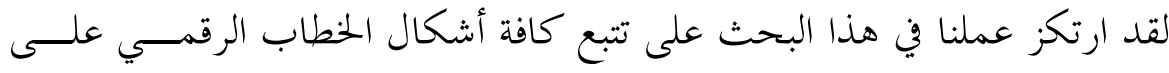

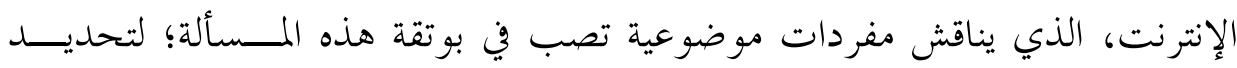

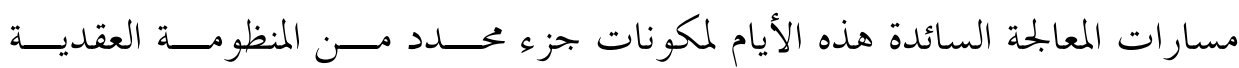

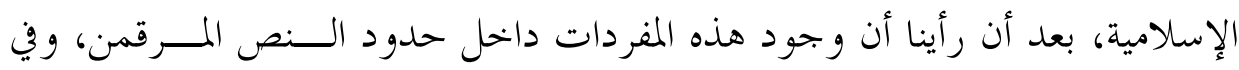

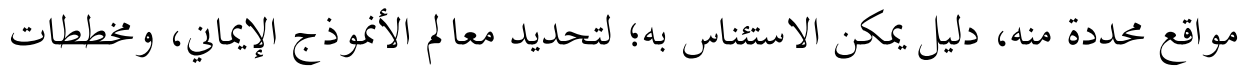

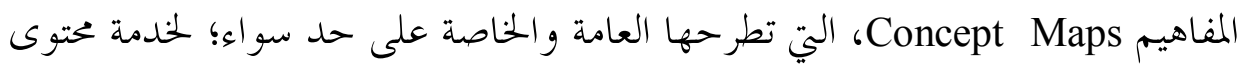

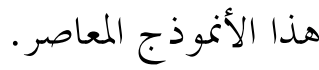


ولتحقيق هذا الغرض اعتمدت آلية ذكية Intelligent Technique وظّفت مــن خلالها محر كات البحث Search Engines (المتو افرة بسخاء على مو اقع الإنترنــــ)؛

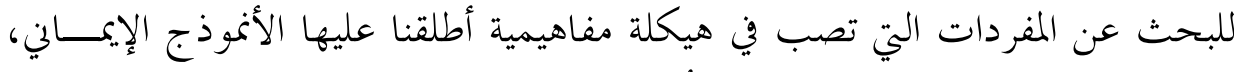

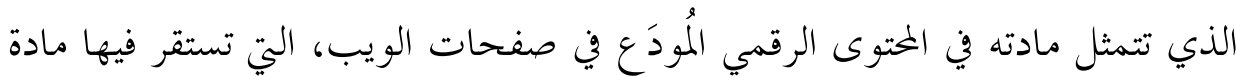

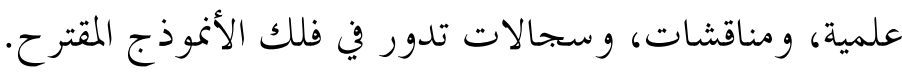

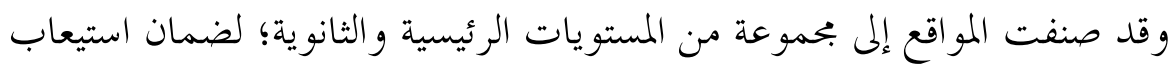

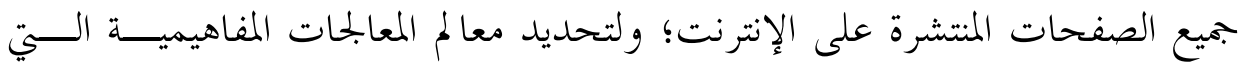
يمارسها المسلم المعاصر على عناصر هذه المسائل، و.بمختلف تشعباها.

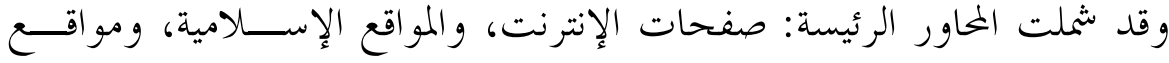

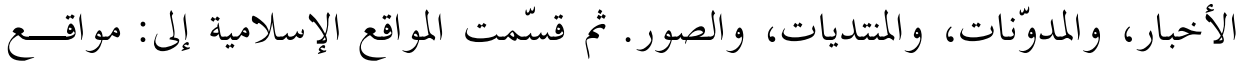

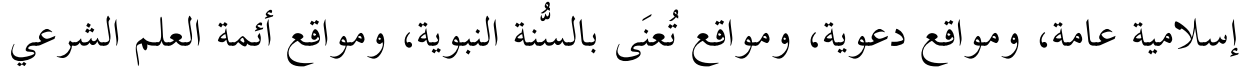

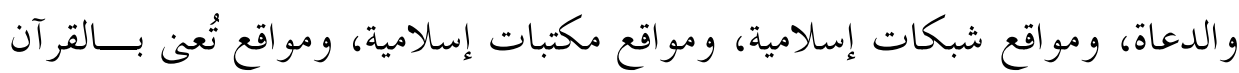

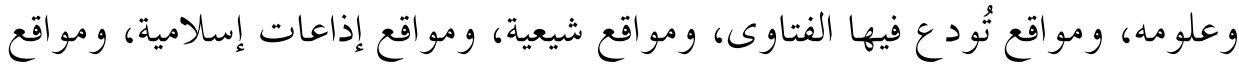

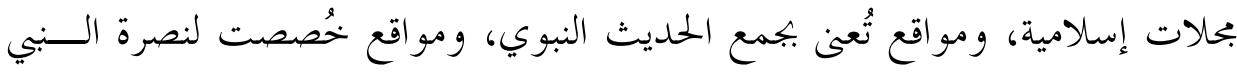

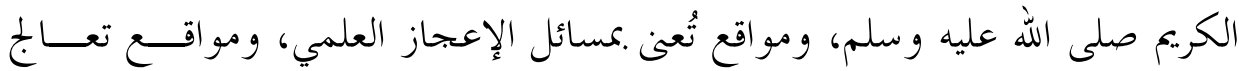

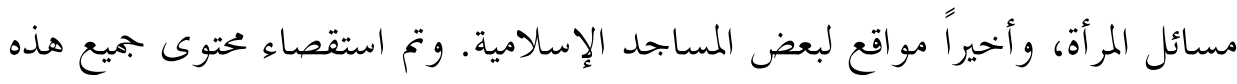

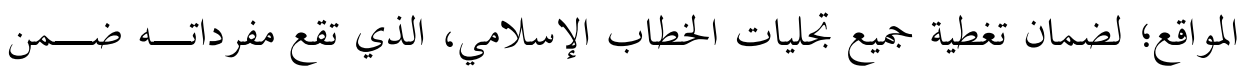

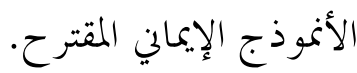

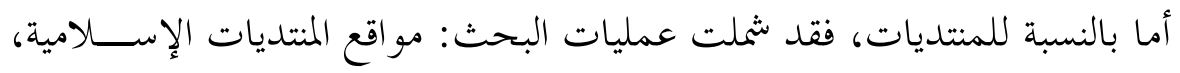

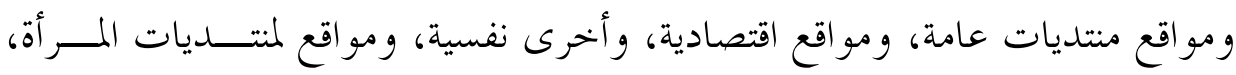
ومنتديات الحاسوب، ومنتديات علمية، ومنتديات تعليمية، ومنتديات طبية، ومنتديات

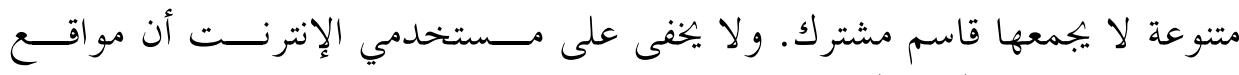

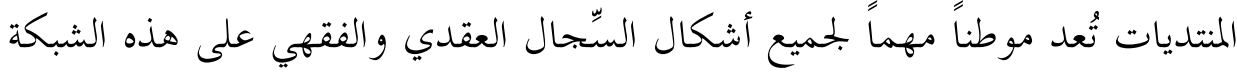

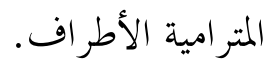


أما محاور البحث عن عناصر المسألة، فقد شملت بحموعة من المحاور التي تم انتقاء

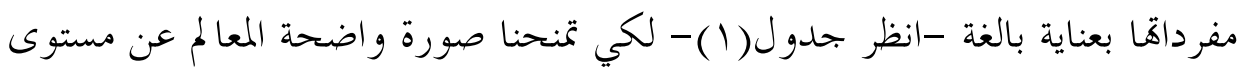

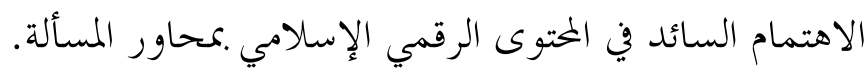
وقد تألفت هذه المحاور من الأطر التالية: الإيمان، وعـــــارض الإيمـــان، ومعــــالم الاتباع، و البدَع و المبتدعين، ورجال الإيمان ومناوئيهم.

\begin{tabular}{|c|c|c|c|c|c|c|c|c|}
\hline \multicolumn{8}{|c|}{ تفاصيل المفردات } & المور \\
\hline \multicolumn{2}{|c|}{ العقيدة } & \multicolumn{2}{|c|}{ التو حيد } & \multicolumn{2}{|c|}{ الإسلام } & \multicolumn{2}{|c|}{ الإيمان } & الإيمان. \\
\hline الردة & \multicolumn{2}{|c|}{ الهوى } & الفجور & الفسق & \multicolumn{2}{|c|}{ الكفر } & الشرك & عوارض الإيمان. \\
\hline \multicolumn{3}{|c|}{ السَّلفية } & \multicolumn{2}{|c|}{ السَّلف } & \multicolumn{3}{|c|}{ السُّنة } & معالم الاتباع. \\
\hline \multicolumn{4}{|c|}{ مبتد ع } & \multicolumn{4}{|c|}{ الِبدعَعة ـ- المُححَثَثة } & و المبتدعين. \\
\hline كافر & مشر & مُرَتَد & فاسق & ضال & مس & مؤ من & داعية & ومناوئيهم. الإيمان \\
\hline
\end{tabular}

جدول (1) - هيكلة عناصر مخطط صفحات الويب للأنموذج الإيماني على مو اقع الإنترنت.

و نظراً للدور الذي تمارسه المفردة بحسب موقعها ضمن مواقع الويب، فقد تمّــت

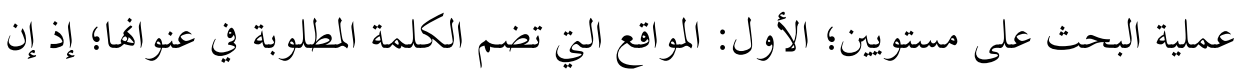

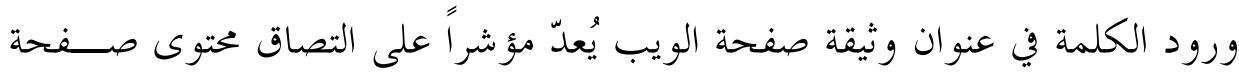
الويب مباشرة بالمفردة ذاتها؛ لأها محور الخطاب السائد في الصفحة. و المستوى الثاني:

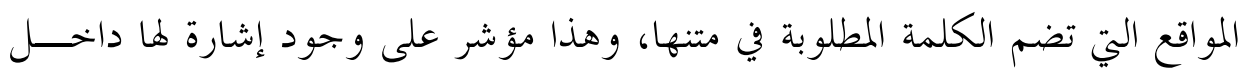
الصفحة، دون أن تكون الكلمة مور اً رئيسياً لمادها. 


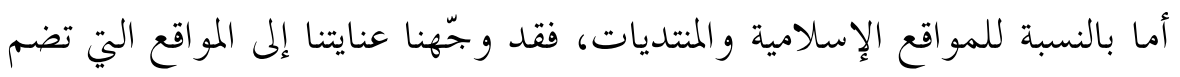

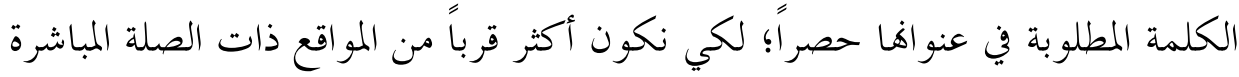

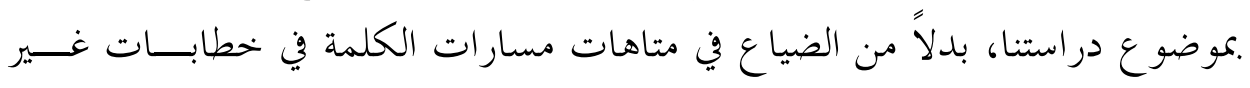
مباشرة.

رابعاً: بيانات الأنموذج الإيماني على مواقع الإنترنت ومخططاته 1 إيانات الأنموذج الإيماني على مواقع الإنترنت:

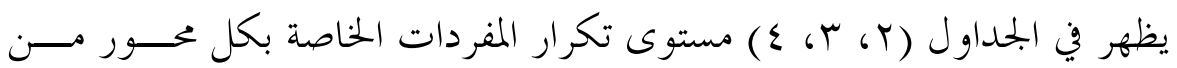

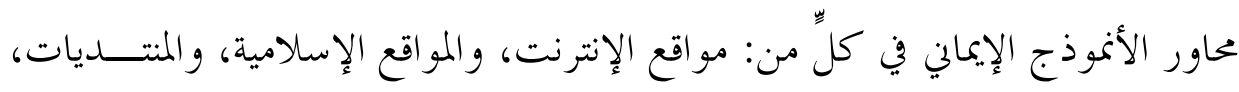

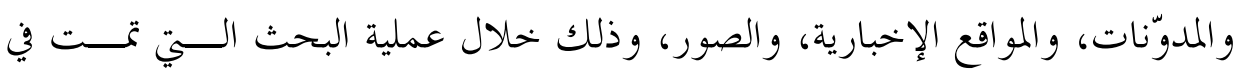

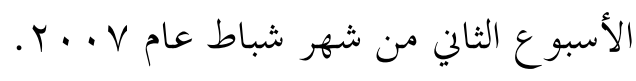

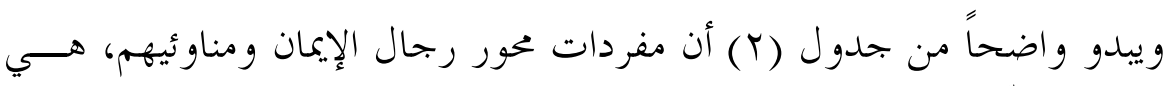

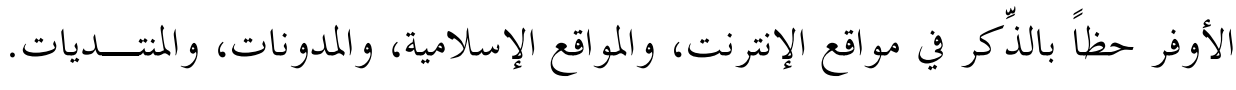

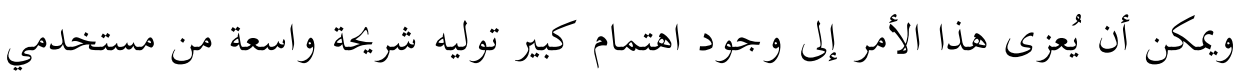

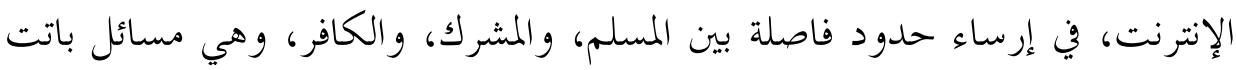

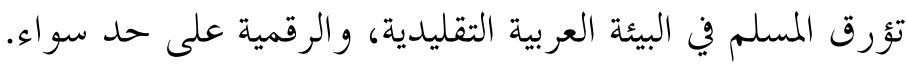

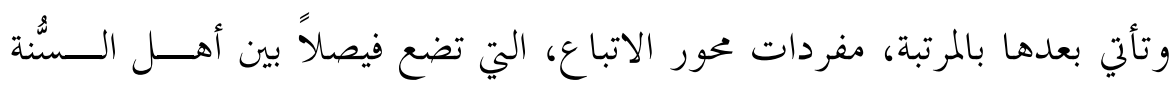

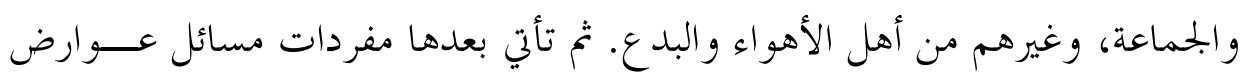

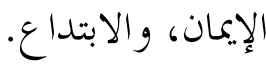

إن الفروق الواضحة بين تكرار ورود مفردات المحاور المختلفة، في قطاعي: عنوان

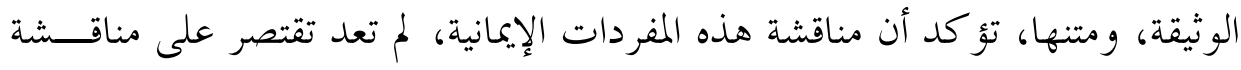

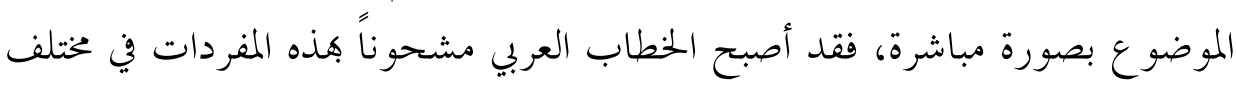


أشكال النصوص المطروحة على صفحات الويب، بعد أن تغلغلت مـــادة الأنـــــذج الإيماني في كثير من مفردات حياة المسلم المعاصر.

وإذا حاولنا قراءة البيانات الموجودة في جدول (؟))، سنجد أن منتديات الــدعوة

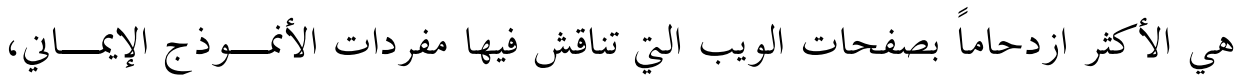

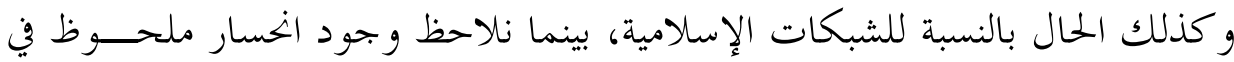
مو اقع فتاوى العلماء.بمعالجة هذه المسائل المهمة. أما بيانات جدول (ع)، فتظهر وجود اهتمام كبير بمفردات الأنموذج الإيمــاني،

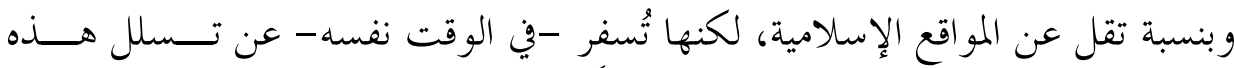
المفردات إلى المنتديات العربية الثقافية، والنفسية، والاقتصادية، والعلمية، و التعليمية.

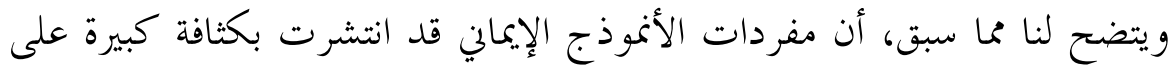

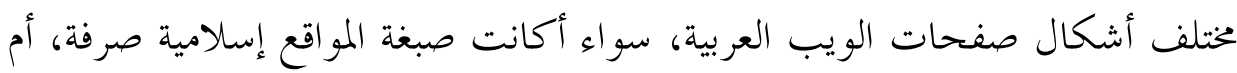

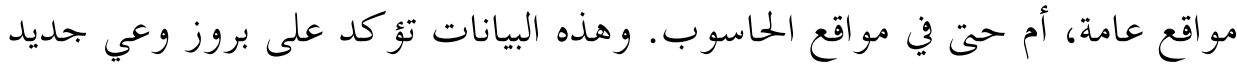

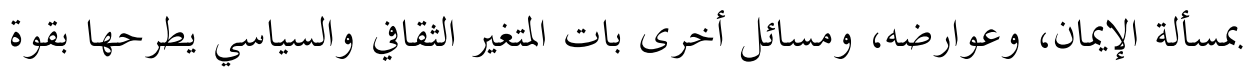

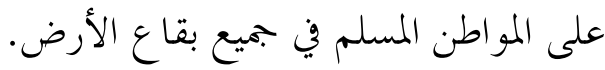
بيد أننا نؤ كد على حقيقة وجود هوّة شاسعة بين الإكثار من ذكر مفــردة مسـن

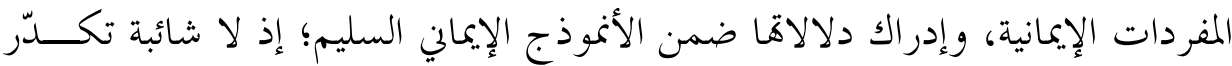

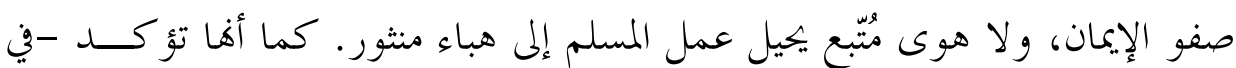

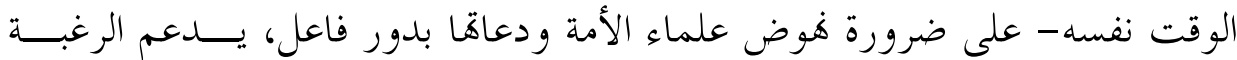

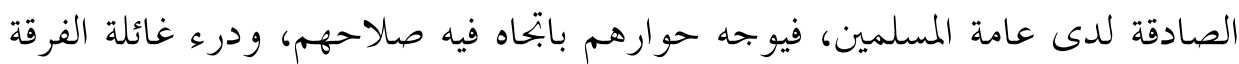
والخلاف بينهم. 


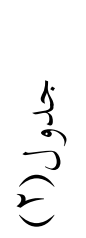

\begin{tabular}{|c|c|c|c|c|c|c|}
\hline & - & 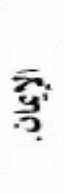 & $\begin{array}{l}\frac{2}{3} \\
\frac{3}{3}\end{array}$ & 豙 & 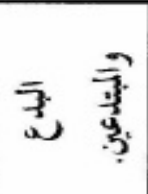 & $\frac{5}{5} \frac{5}{5}$ \\
\hline & 鵦 & 管 & $\begin{array}{l}\overline{2} \\
\text { సี่ }\end{array}$ & 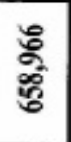 & $\frac{\curvearrowleft}{\mathfrak{n}}$ & 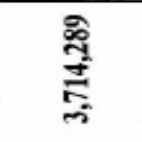 \\
\hline & $\frac{3}{2} \frac{3}{3}$ & 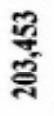 & $\frac{5}{5}$ & $\frac{\vec{F}}{\stackrel{7}{F}}$ & 결 & $\begin{array}{l}\vec{\sigma} \\
\bar{\sigma} \\
\bar{F}\end{array}$ \\
\hline $\begin{array}{c}-9 \\
\frac{2}{3}\end{array}$ & & $\underset{\text { స్ర }}{\stackrel{0}{్}}$ & $\stackrel{m}{\leftrightarrows}$ & $\Xi$ & $\cong$ & 菍 \\
\hline 尔 & 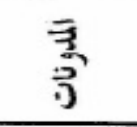 & $\begin{array}{l}\text { \% } \\
\text { 䒬 }\end{array}$ & $\frac{m}{\sqrt{2}}$ & $\begin{array}{l}\text { 堼 } \\
\text { 守 }\end{array}$ & 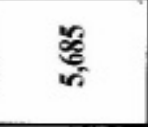 & 谷 \\
\hline & 武 & 椐 & క్ & $\begin{array}{l}\text { \%ँ } \\
\text { ले }\end{array}$ & $\underset{\text { न }}{\vec{F}}$ & $\frac{\sqrt{6}}{2}$ \\
\hline & 冎 & 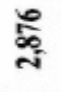 & 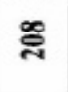 & $\underset{F}{F}$ & $\bar{\Xi}$ & సัำ \\
\hline & $\begin{array}{l}\overline{7} \\
3 \\
3\end{array}$ & 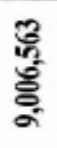 & 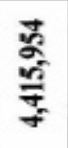 & $\begin{array}{l}\sqrt{5} \\
5 \\
5 \\
\infty \\
\infty\end{array}$ & 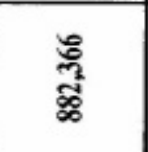 & $\begin{array}{l}\frac{2}{2} \\
\frac{8}{2} \\
= \\
=\end{array}$ \\
\hline & $\frac{3}{3} \frac{3}{3}$ & 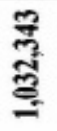 & 登 & 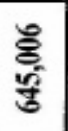 & $\begin{array}{l}\text { ב̀ } \\
\text { בี }\end{array}$ & 豀 \\
\hline $\begin{array}{l}-3 \\
3 \\
3\end{array}$ & 㞼 & בิ & E & ప్ & 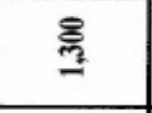 & $\frac{7}{\text { 落 }}$ \\
\hline 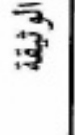 & 咅 & 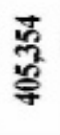 & 욿 & $\begin{array}{l}\text { 管 } \\
\text { 总 } \\
0\end{array}$ & $\begin{array}{l}\mathscr{0} \\
\underset{\%}{0} \\
\stackrel{్}{0}\end{array}$ & $\begin{array}{l}\text { gे } \\
\text { ô } \\
\text { ज्ञ }\end{array}$ \\
\hline & 就 & $\begin{array}{l}5 \\
\text { 点 }\end{array}$ & 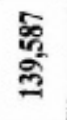 & $\begin{array}{l}\text { స్షี } \\
\text { స్ન }\end{array}$ & $\frac{\bar{\sigma}}{\vec{p}}$ & $\frac{\bar{\sigma}}{\bar{E}}$ \\
\hline & 平 & 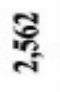 & สี & $\underset{F}{F}$ & $\Xi$ & 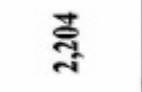 \\
\hline
\end{tabular}




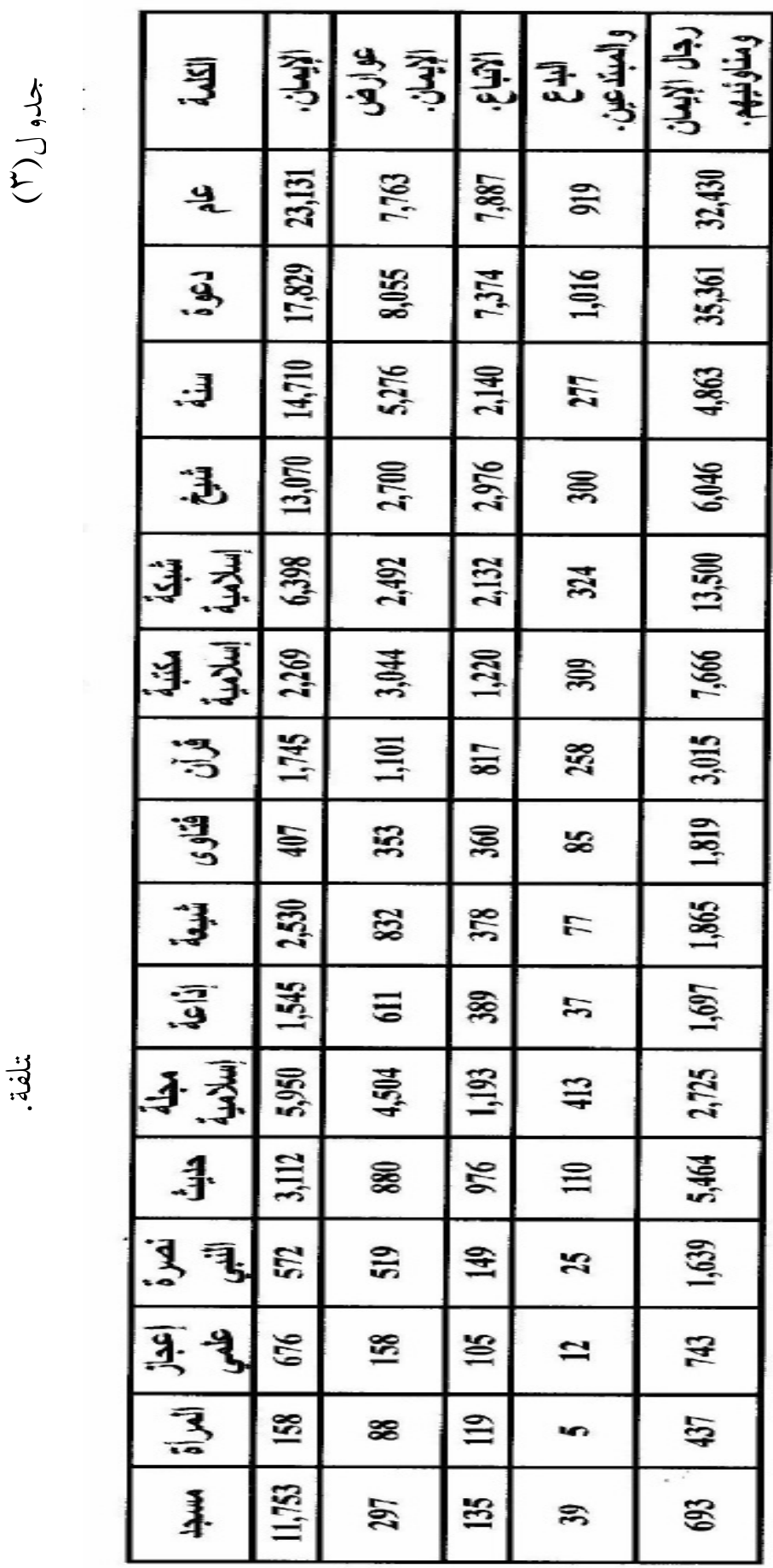


क

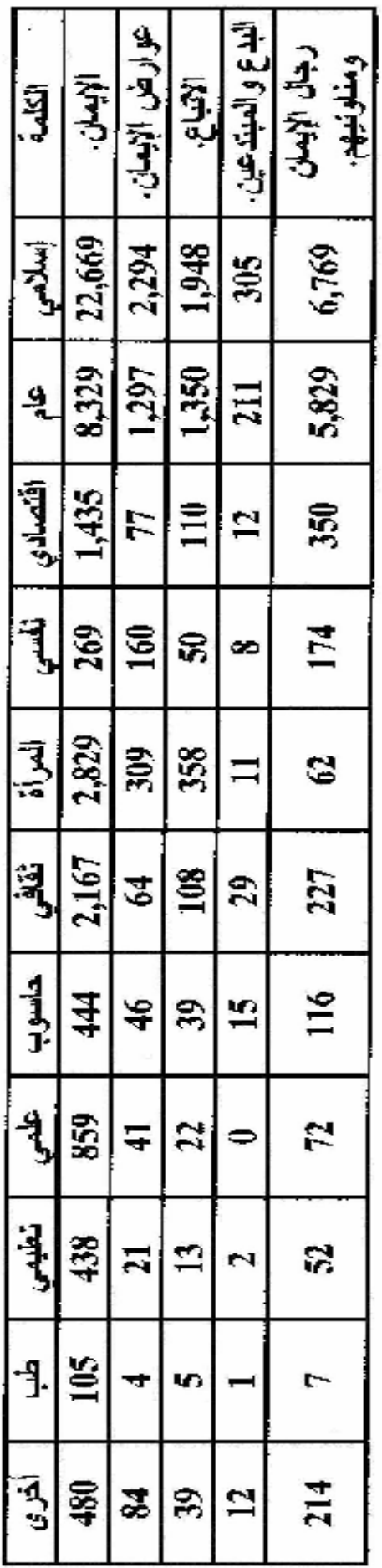




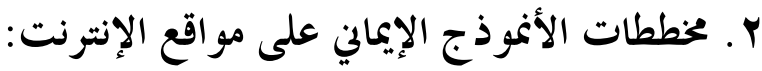

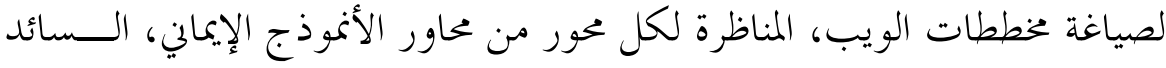

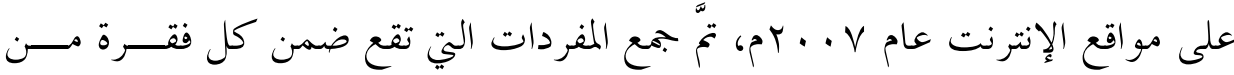

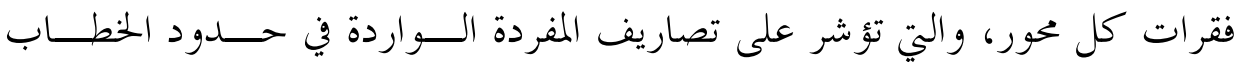
المطروح (مثل: مسلم، مسلمون، مسلمين). وقد أُعدّت ثلاثة أصناف من المخططات، بحيث يُظهر الــصنف الأول انتــشار

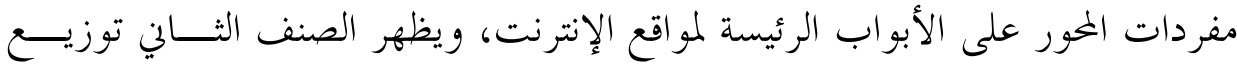

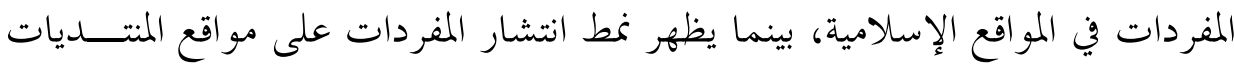
العربية في الصنف الثالث من هذه المخططات.

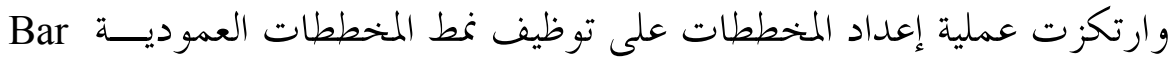
Chart

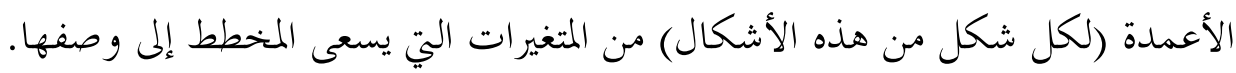

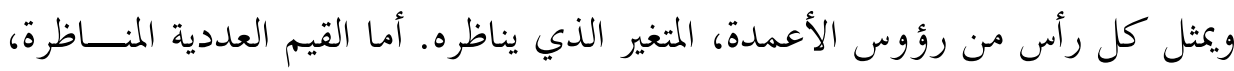

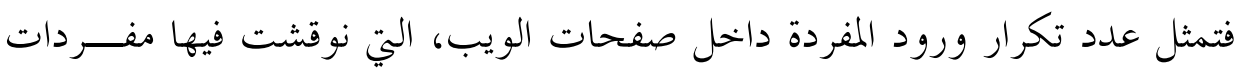

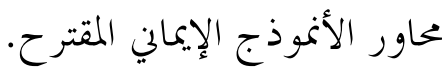

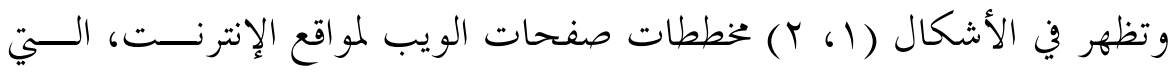

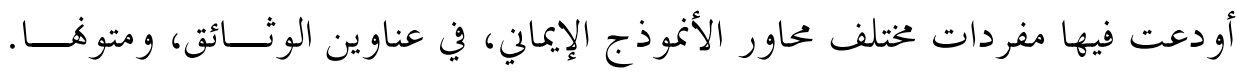

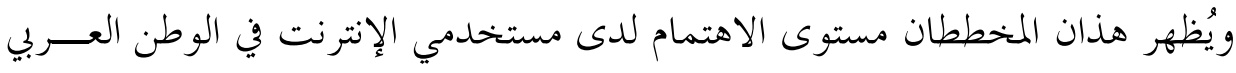

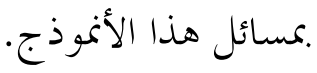

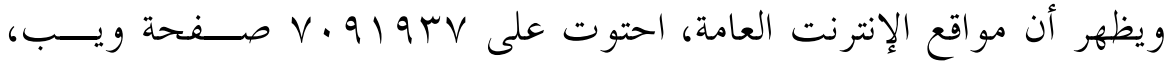
ضمت في عناوينها مفردات الأنموذج الإمماني، بينما توجد الإند

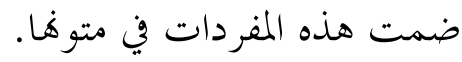




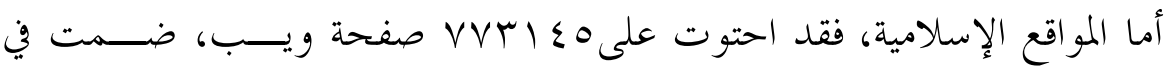

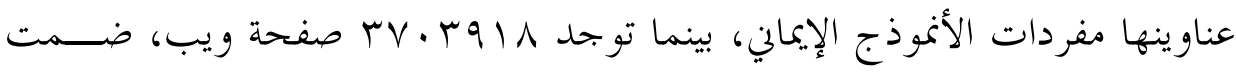

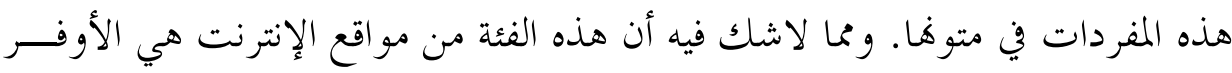
حظاً في تناول هذه المسألة، بحكم هو ديتها و واهتمامات رو رو ادها.

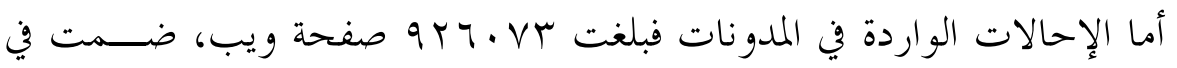

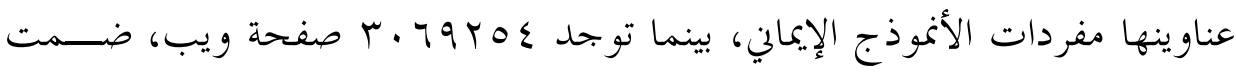

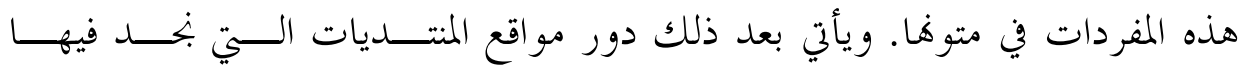
أن الو9 \ اب صفحة ويب، ضمت في عناوينها مفردات الأنموذج الإيماني، بينما توجد

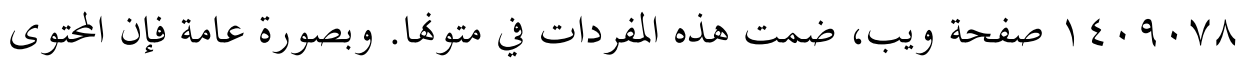
الرقمي المطروح في هذه المنتديات، لا يزيد عن كونه بجموعة تعليقات ترد هنا أو هناك أثناء المناقشات العامة، التي يطرح خلالها رواد الماد المنتديات مسائل ذات صلة بمفــــردات

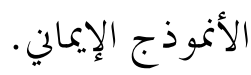

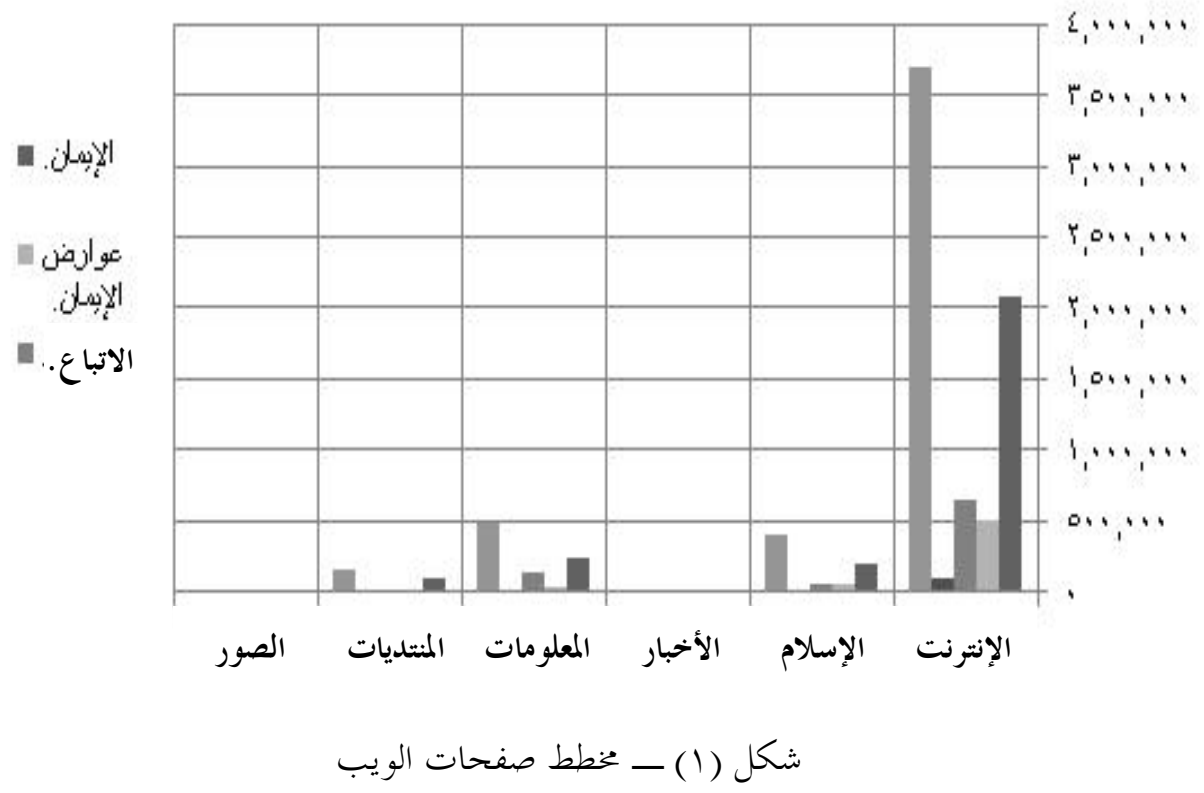

بحسب ورود كلمات المحاور في عناو ين الوثائق المنتشرة على مواقع الإنترنت المختلفة. 

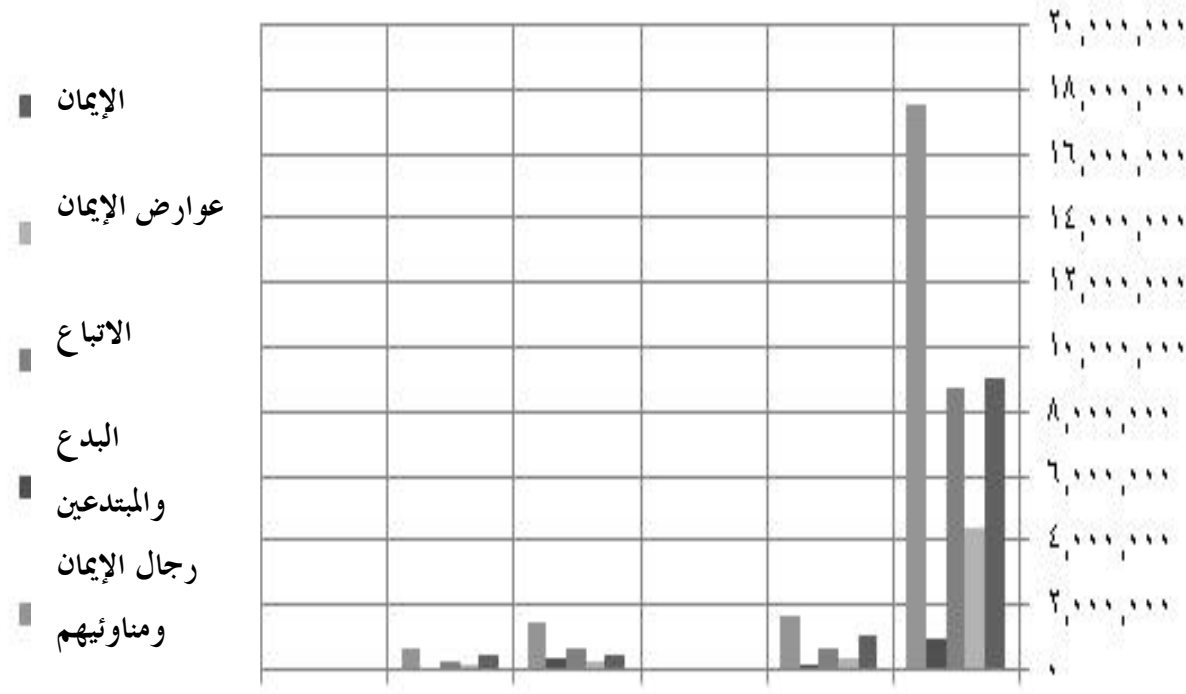

الإنترنت الإسلام الأخبار المعلومات المنتديات الصور

شكل (T) - خ خطط صفحات الويب

بحسب ورود كلمات المحاور في متن الوثائق المنتشرة على مواقع الإنترنت المختلفة.

أما إذا حاولنا تحليل تفاصيل مخطط صفحات الويب في المواقع الإسلامية (انظــــ

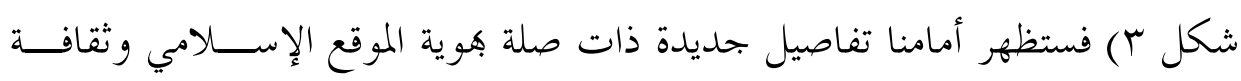
رواده.

ويبدو واضحاً أن مساحة انتشار استخدام المفردات الإيمانية قد توسعت، مقارنة

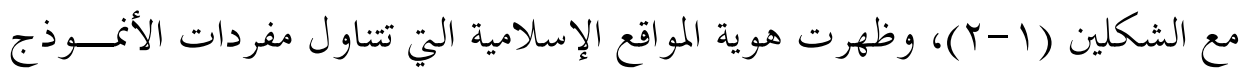
الإيماني .مو اقعها المنتشرة على الإنترنت.

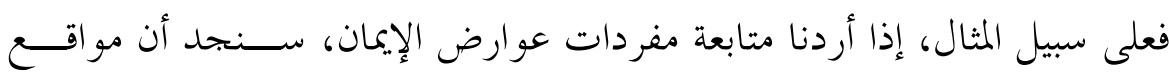

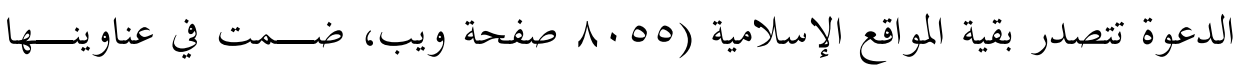

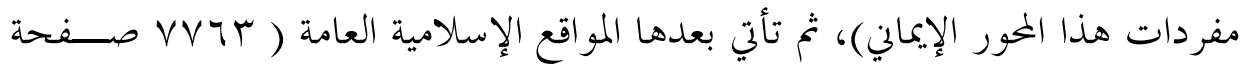

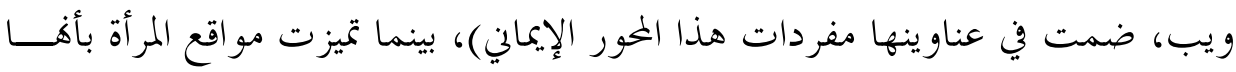


الأقل اهتماماً هذذه المسألة (17 ا صفحة ويب، ضمت في عناوينها مغردات الأنموذج الإيماني).

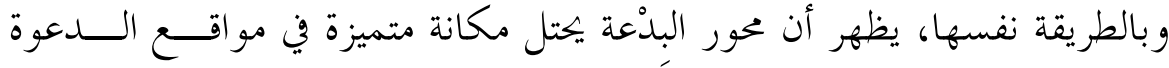

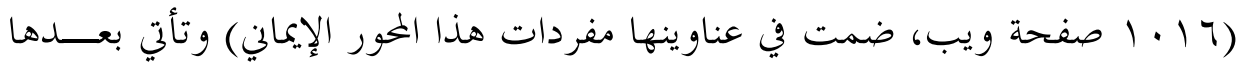

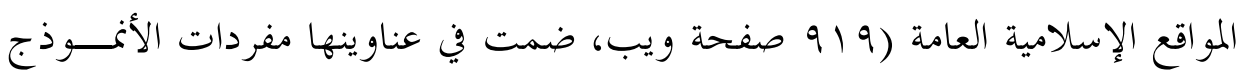
الإيماني).

كذلك يمكن تمييز أكثر محاور الأنموذج الإيماني، التي تستأثر باهتمام المسلم المعاصر

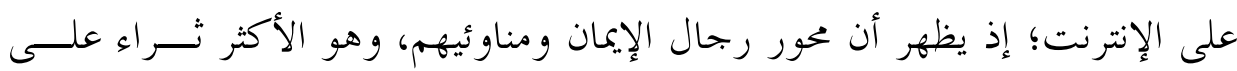

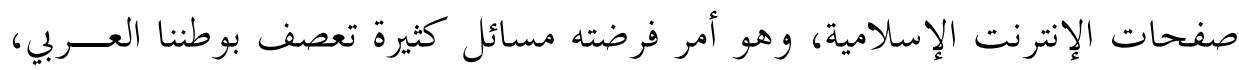

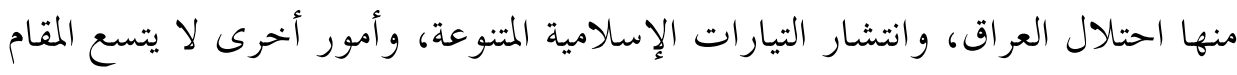
لذكرها.

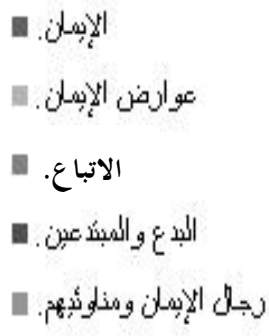

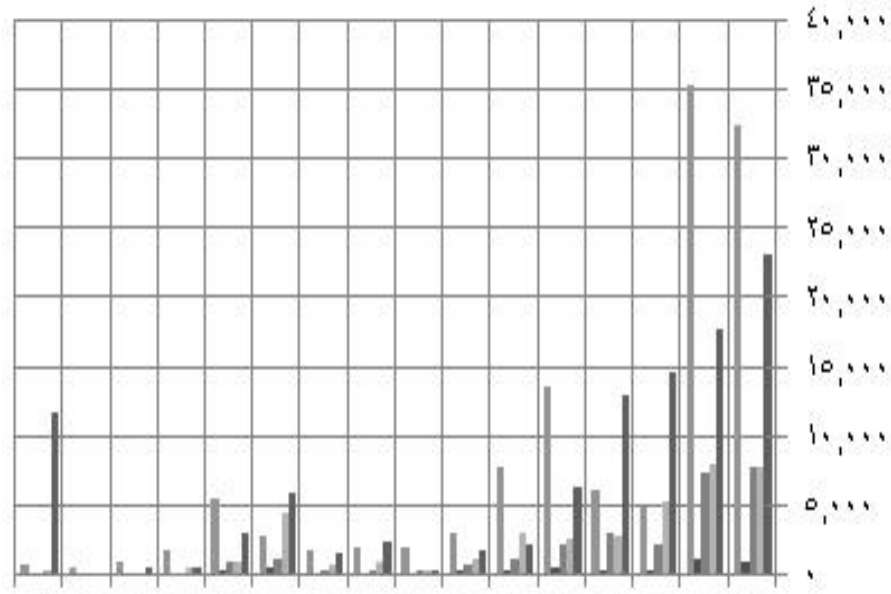

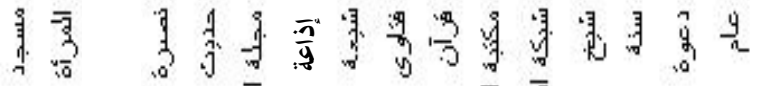

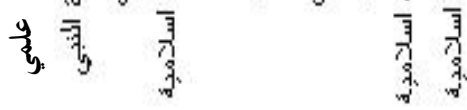

$$
\text { شكل (r) - مخطط صفحات ويب المواقع الإسلامية }
$$


وفي الوقت نفسه، يبدو جلياً أن امتداد ساحة النقاش الإيماني قد ارتبطت .مسائل

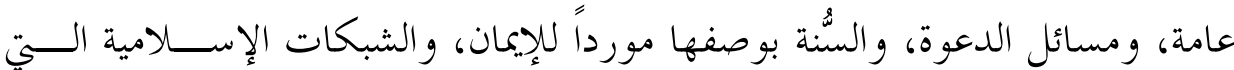

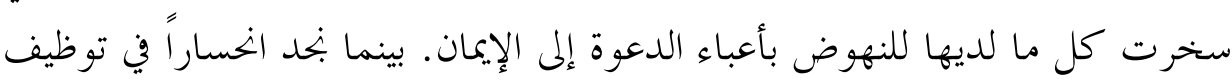
النص القر آني، والفتاوى، و البحلات الإسلامية المنتشرة على الإنترنت، في مناقشة هذه

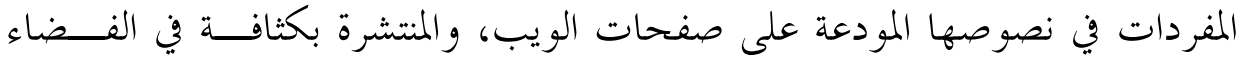
المعلوماتي لإنترنيت.

Iالإنب-ن.

تو ارضن الإبدانة. الاتباع.

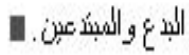
1.

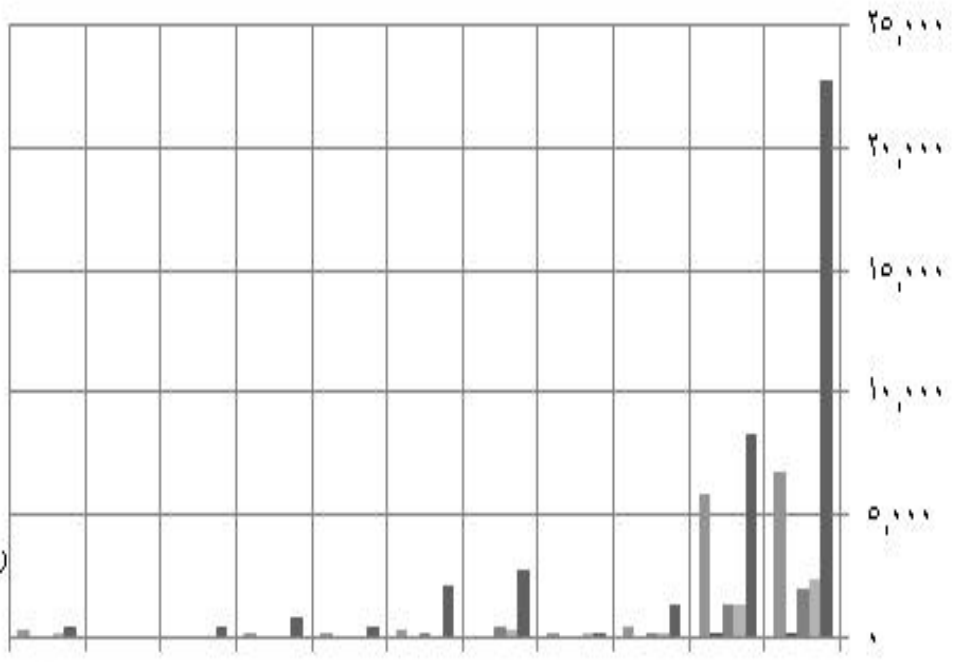

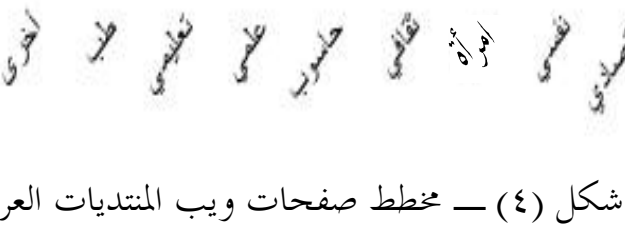

$$
\begin{aligned}
& \text { التي تناقش مفردات محاور الأنموذج الإيماني. }
\end{aligned}
$$

أما مخطط صفحات الويب الخاصة بالمنتديات العربية (انظر شكل ع)، فيظهر لنا

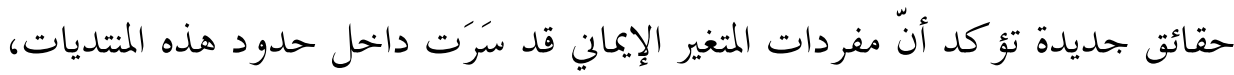

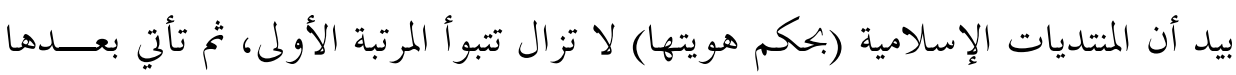

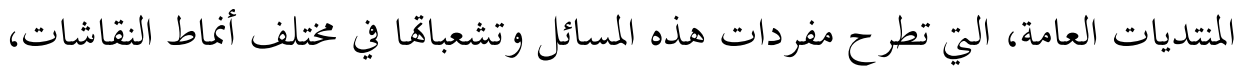
بينما لم تخل بقية المنتديات-حتى العلمية الصرفة و التعليمية- منها. 
وإذا أردنا أن نحدد نمط مناقشة مسائل محور رجال الإيمان ومناوئيهم -على سبيل

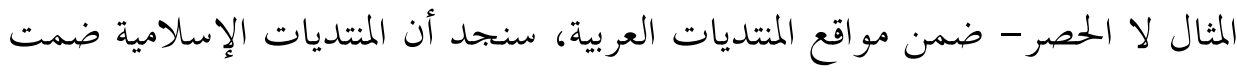

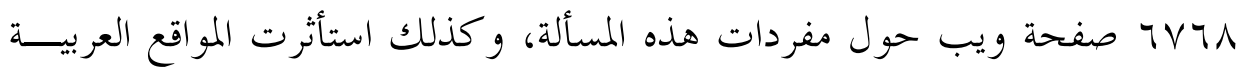

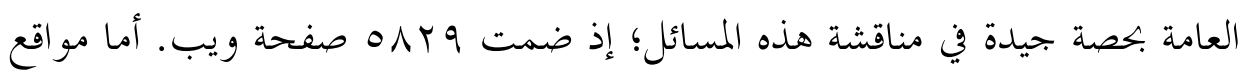

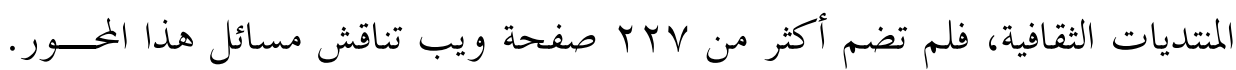

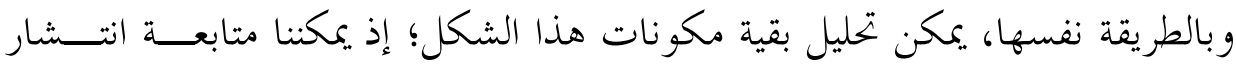

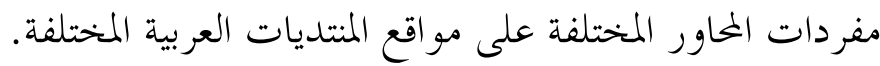

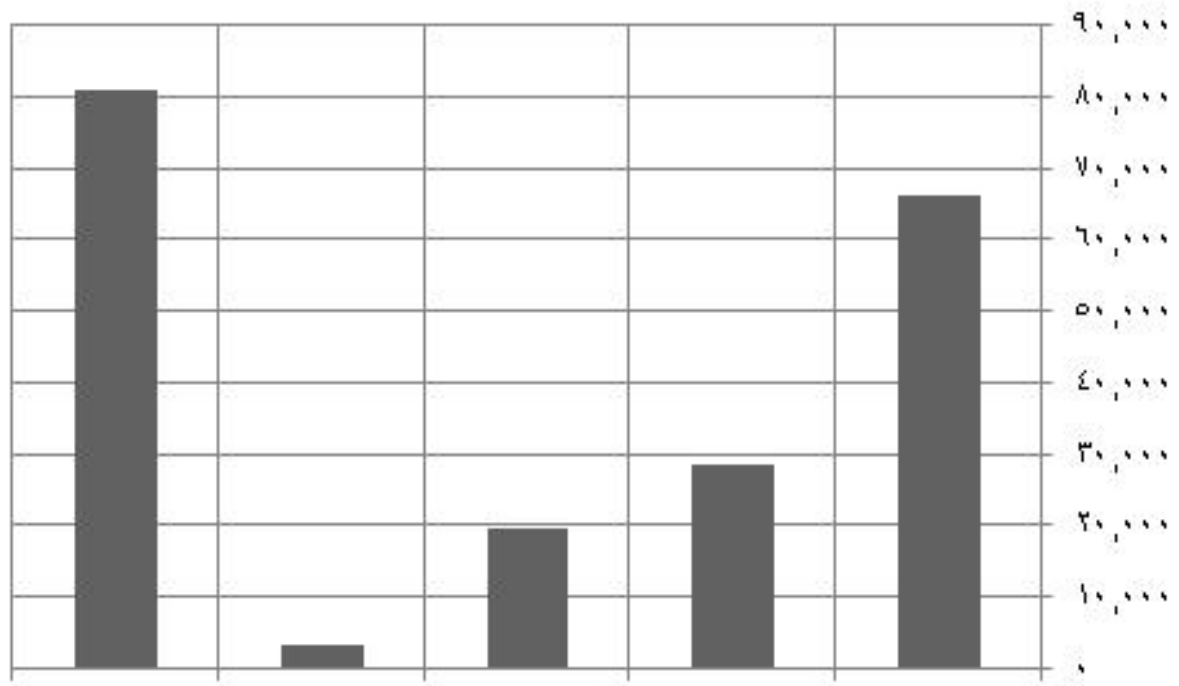

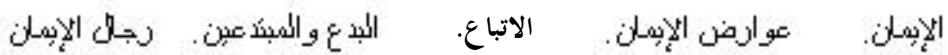
ونذوئينه.

شكل (0) - مخطط صفحات ويب خطاب أئمة الأمة وعلمائها حول محاور الأنموذج الإيماني على مواقع الإنترنت العربية.

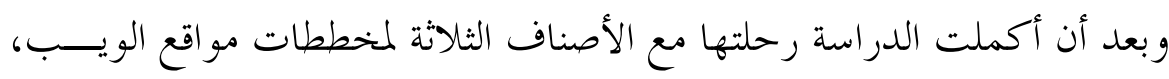

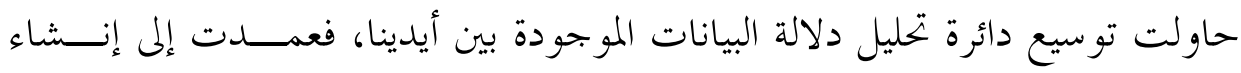

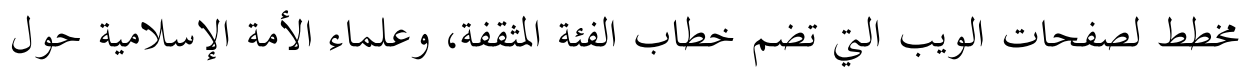


المسائل ذات الصلة بمحاور الأنموذج الإيماني (انظر شكل 0). وقد ضمت هذه المواقع كلاً من مواقع: الشيوخ، والفتاوى، والشبكات الإسلامية المتخصصة.

ويظهر أن مساحة الاهتمام قد توسعت بوضوح من حيث عدد تكرار المفردات

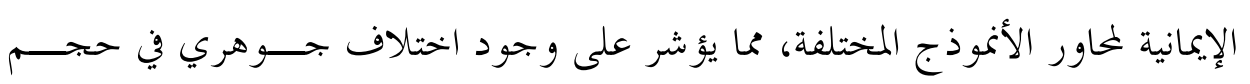

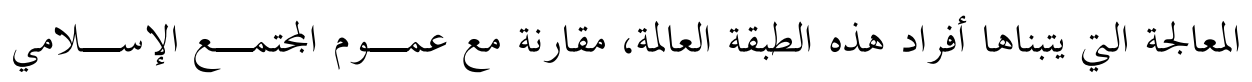

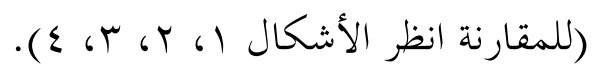

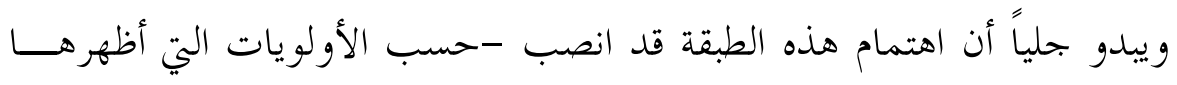

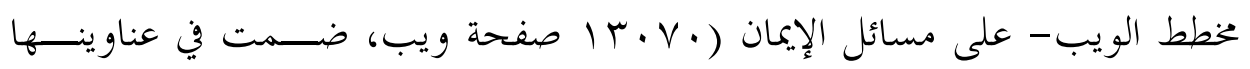

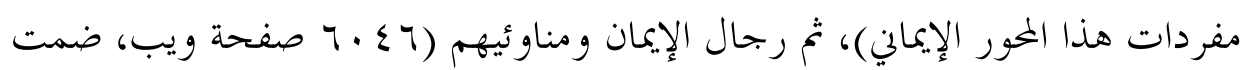

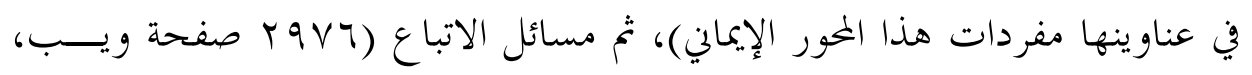

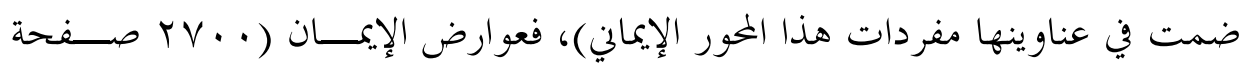

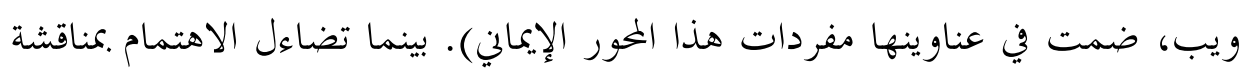

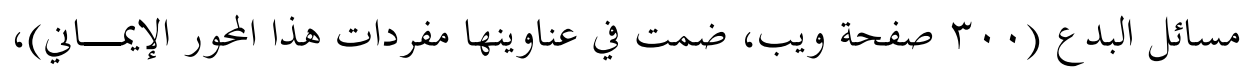

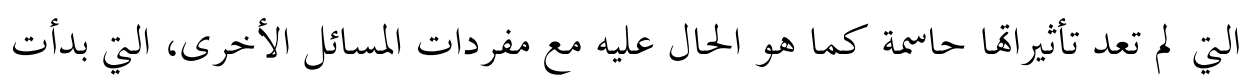
تعصف بالأنموذج الإيماني للمسلم المعاصر في هذه الأيام.

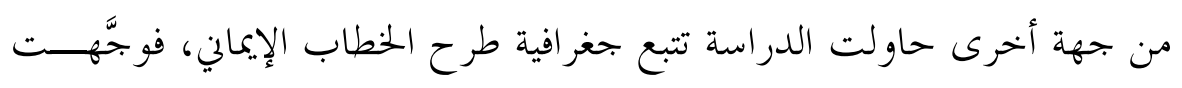
عنايتها لتحديد هوية البلدان العربية، ومستوى توظيف مفردات محاور الأنموذج الإيماني

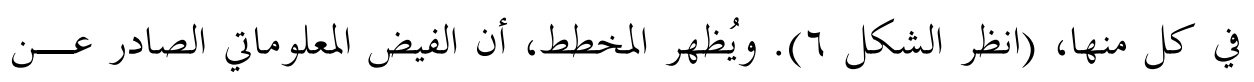

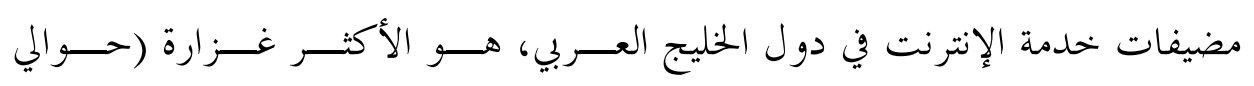

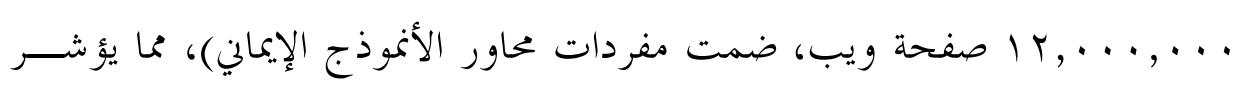

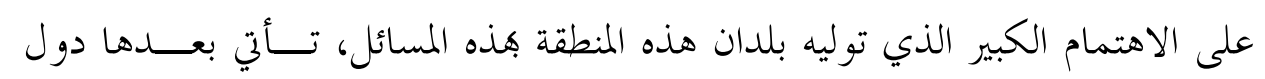




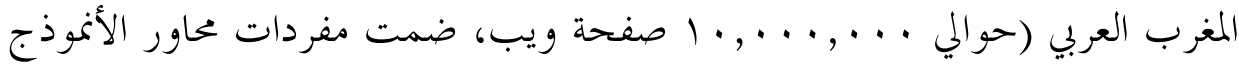
الإيماني)، في حين تأتي العراق وبلاد الشام في المرتبة الأخيرة بالنسبة لحجم الاهتمــام

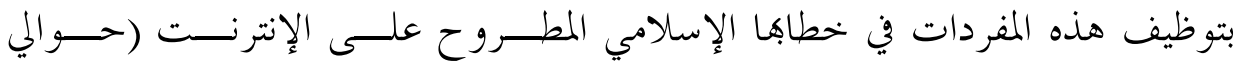
. ^ صفحة ويب، ضمت مفردات محاور الأنموذج الإيماني). . . . . . .

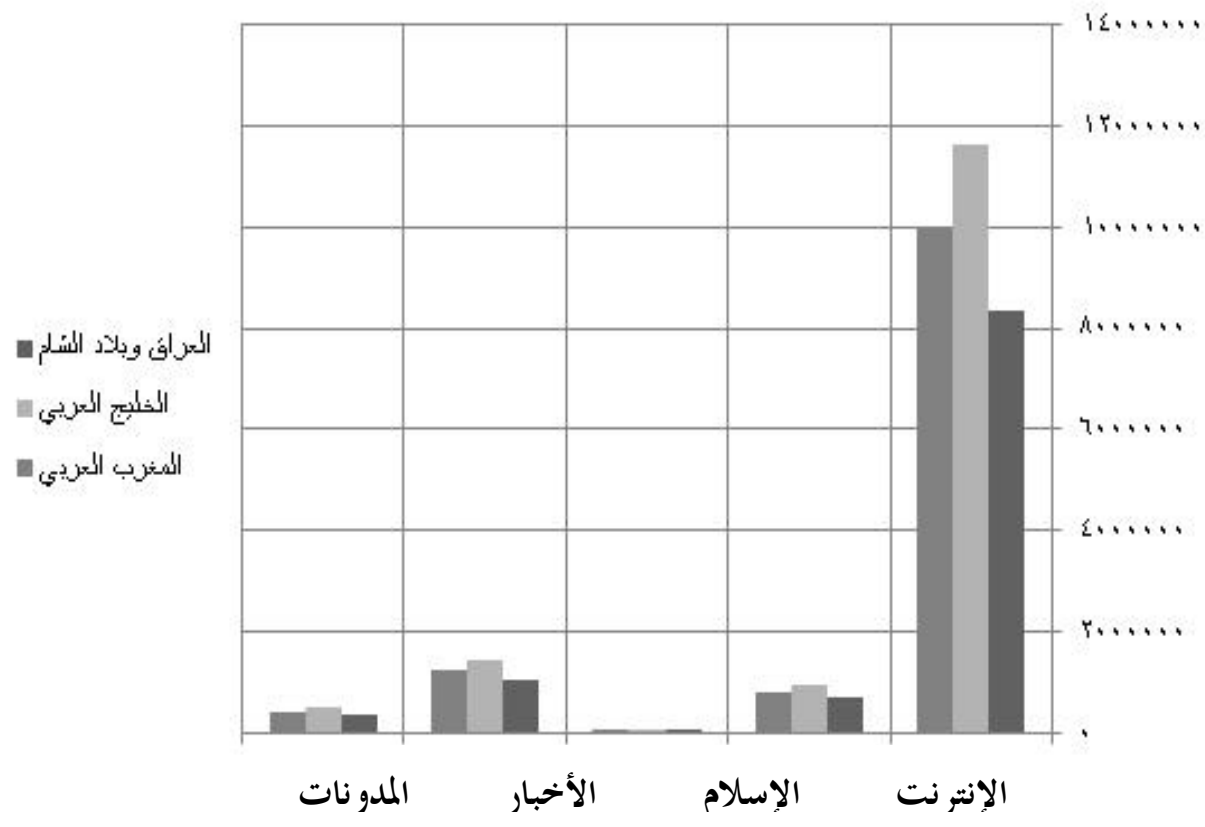

شكل (T) - خ خطط صفحات الويب

التي تناقش الأنموذج الإيماني في مناطق الدول العربية.

بالمقابل، يظهر وجود تكافؤ في حجم المواقع الإسالامية في مناقشة مفردات المحاور

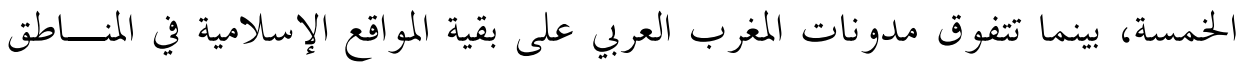

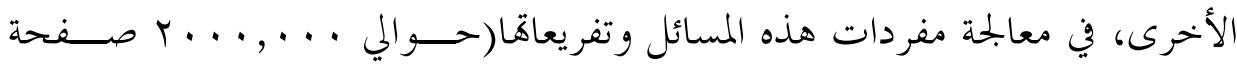
ويب، ضمت مفردات محاور الأنموذج الإيماني). 


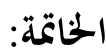

لقد تحولت حصيلتنا المعرفية الإسلامية، من دائرة المدوّن على مادة الورق إلى البيئة

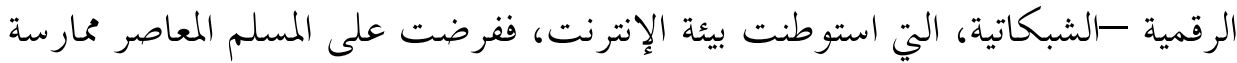
جملة من المعالجات المفاهيمية المبتكرة على النصوص الرقمية لمواردنا.

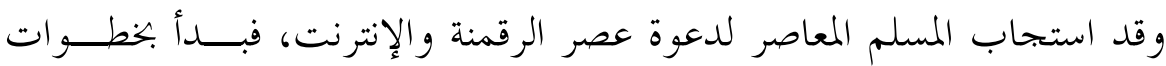

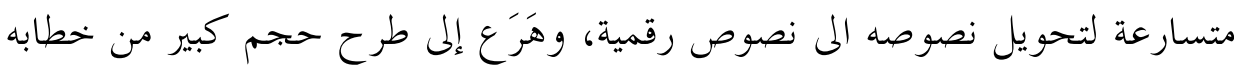
الإسلامي على مواقع الشبكة العنكبوتية World-Wide-Web لإنترنيت. إن البيئة المفتوحة التي تتميز هها شبكة الإنترنت، منحت للكثيرين فرصسـة ســـهلة

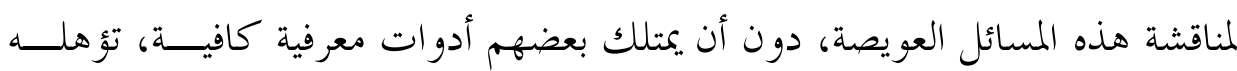

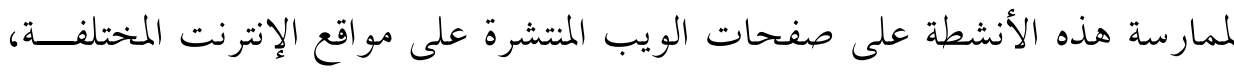

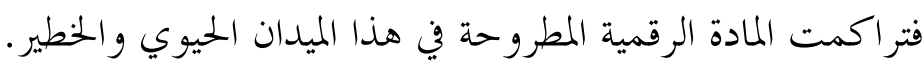
لقد أظهرت المخططات المفاهيمية للآراء ذات الصلة بالمنظومة العقدية الإسلامية،

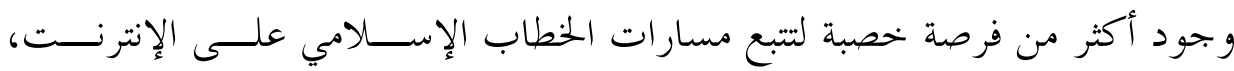

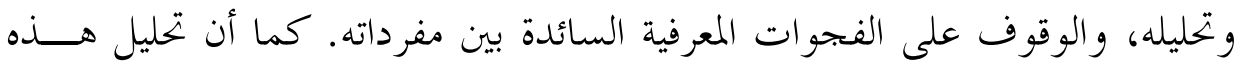

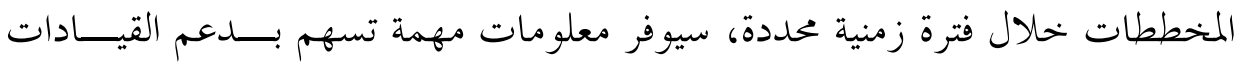

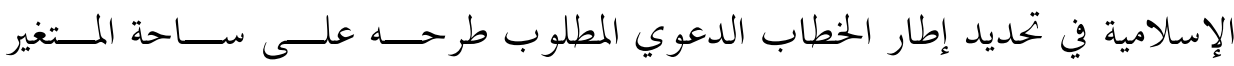

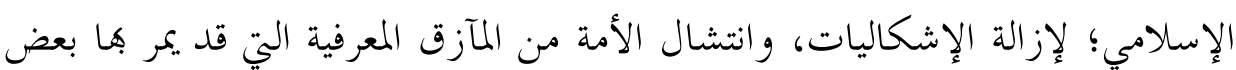

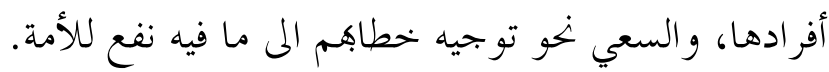

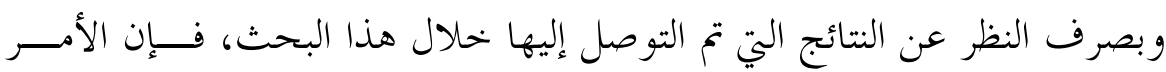

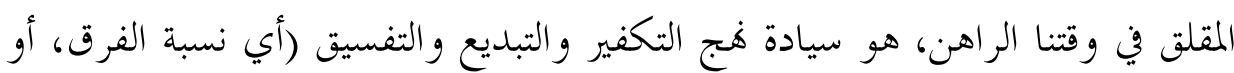

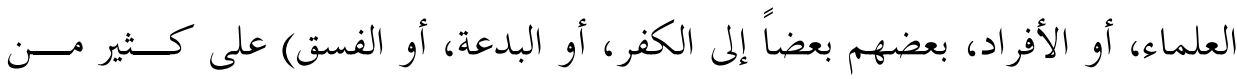

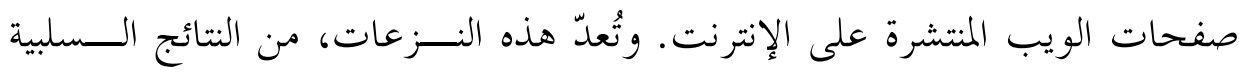

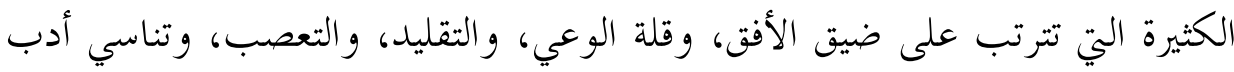


الاختلاف، وروح العلم والتعليم والموضوعية، وأدب الحو ار والجحدال بالتي هي أحسن،

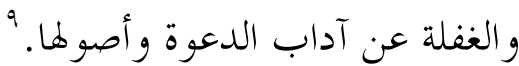

ولعل من أهم أسباب الإسراف في تعاطي ظاهرة التكفير بين المــسلمين، تلـــك

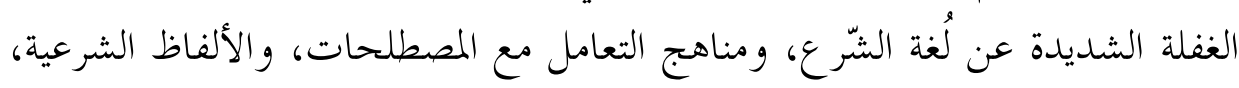

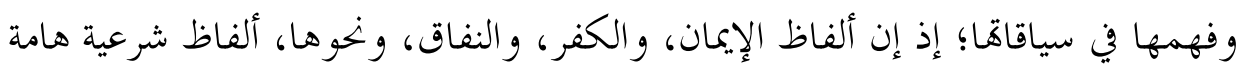

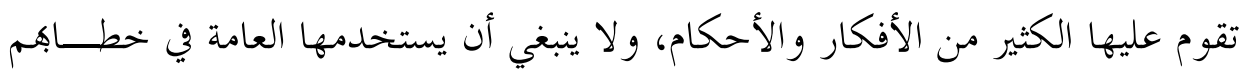
اليومي، لما له من أثر في بث الفرقة بين أبناء الأمة الإسلامية. 